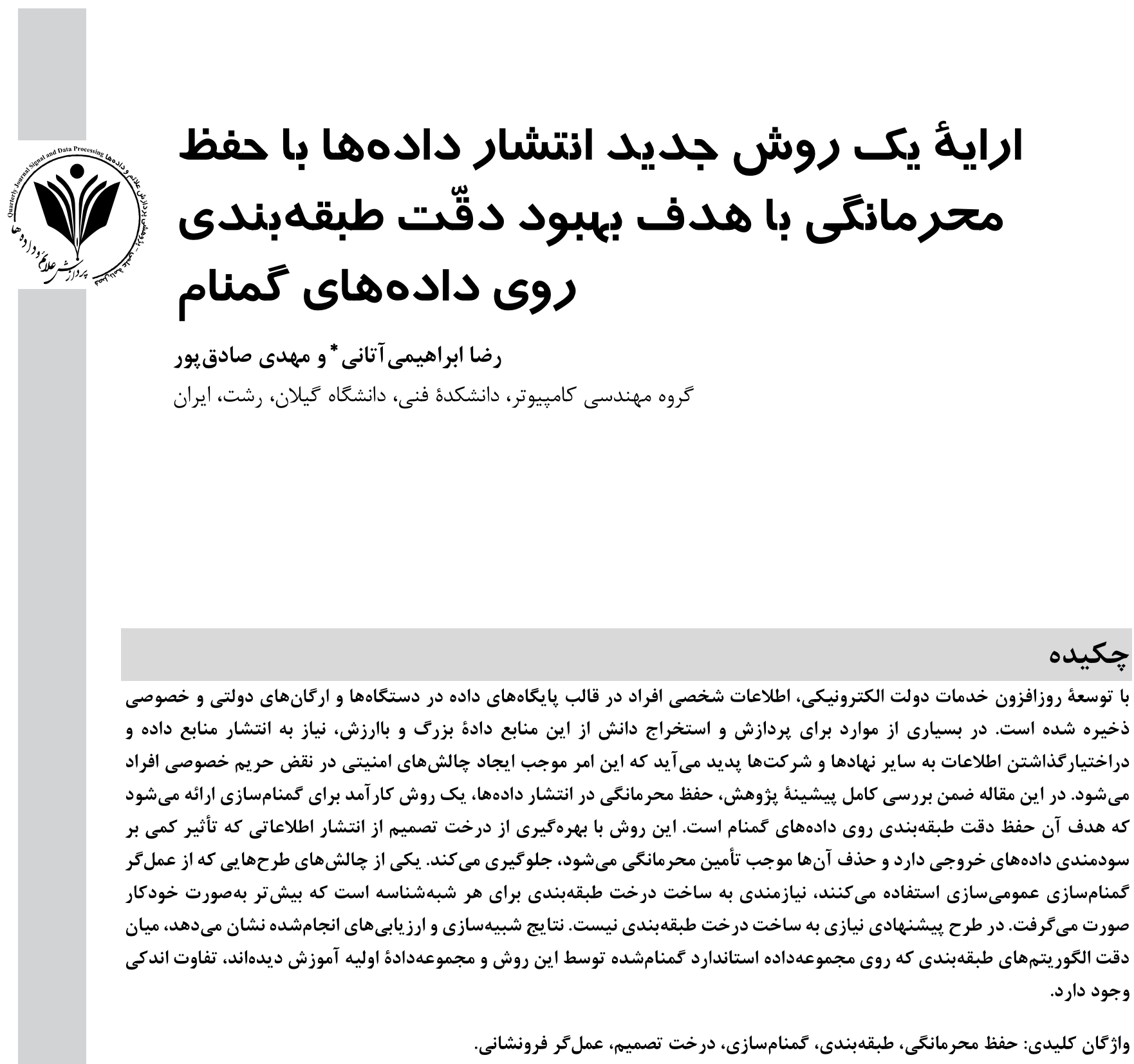

\title{
A New Privacy Preserving Data Publishing Technique Conserving Accuracy of Classification on Anonymized Data
}

\author{
Reza Ebrahimi Atani* \& Mehdi Sadeghpour \\ Department of Computer Engineering, University of Guilan, Rasht, Iran
}

\begin{abstract}
Data collection and storage has been facilitated by the growth in electronic services, and has led to recording vast amounts of personal information in public and private organizations databases. These records often include sensitive personal information (such as income and diseases) and must be covered from others access. But in some cases, mining the data and extraction of knowledge from these valuable sources, creates the need for sharing them with other organizations. This would bring security challenges in user's privacy. The concept of privacy is described as sharing of information in a controlled way. In other words, it decides what type of personal information should be shared and which group or person can access and use it. "Privacy preserving data publishing" is a solution to ensure secrecy of sensitive information in a data set, after publishing it in a hostile environment. This process aimed to hide sensitive information and keep published data suitable for knowledge discovery techniques. Grouping data set records is a broad approach to data anonymization. This technique prevents access to sensitive attributes of a specific record by eliminating the distinction between a
\end{abstract}

Corresponding author

* نويسنده عهدهدار مكاتبات 
number of data set records. So far a large number of data publishing models and techniques have been proposed but their utility is of concern when a high privacy requirement is needed. The main goal of this paper to present a technique to improve the privacy and performance data publishing techniques. In this work first we review previous techniques of privacy preserving data publishing and then we present an efficient anonymization method which its goal is to conserve accuracy of classification on anonymized data. The attack model of this work is based on an adversary inferring a sensitive value in a published data set to as high as that of an inference based on public knowledge. Our privacy model and technique uses a decision tree to prevent publishing of information that removing them provides privacy and has little effect on utility of output data. The presented idea of this paper is an extension of the work presented in [20]. Experimental results show that classifiers trained on the transformed data set achieving similar accuracy as the ones trained on the original data set.

Keywords: Privacy preservation, Data sharing, Anonymization, Classification, Decision tree, Suppression.
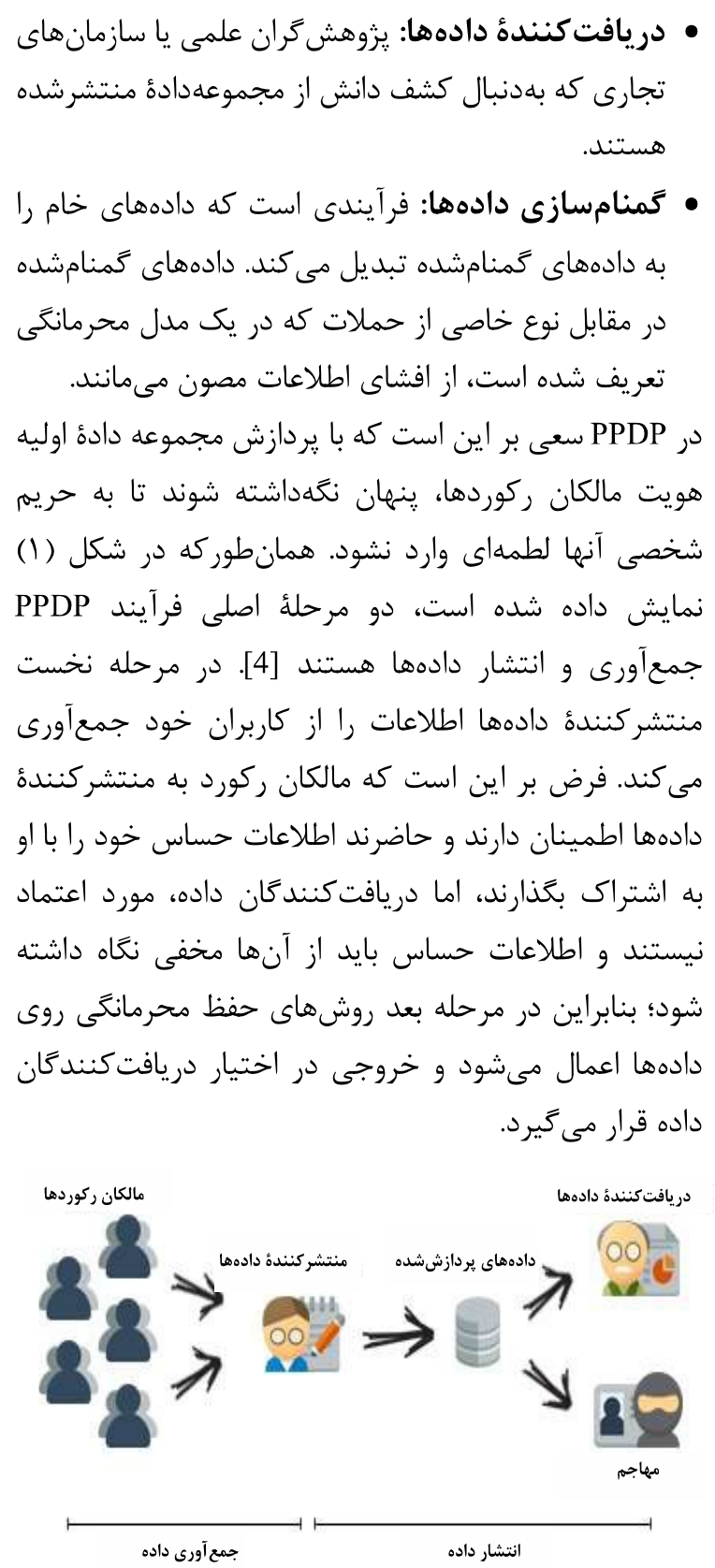

(شكل - (): جمع آورى و انتشار دادهها

(Figure-1): Data collection and data publishing

\section{- - - مقلمّهـ}

با توسعه و نفوذ هر جها بيشتر خدمات الكترونيكى در زندگى

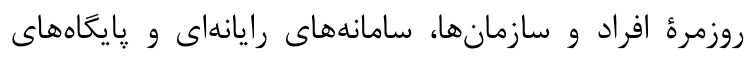

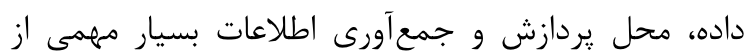

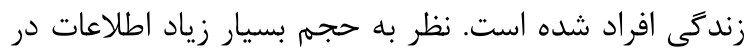

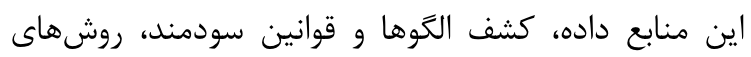
دادهكاوى را به ابزارى كليدى براى استفاده از اين منابع بارزشي داده تبديل كرده است. مالكان اين مجموعهدادهاديا

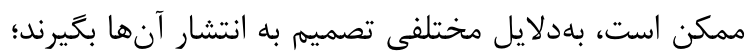

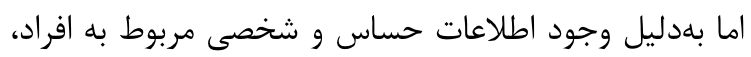
نمىتوانند اين دادها را بهصورت خام انتشار دهند. فرآ آيند

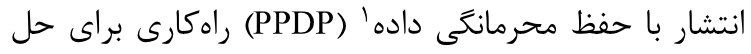
اين مشكل در محيطهاى غيرقابل اعتماد است [1,4].

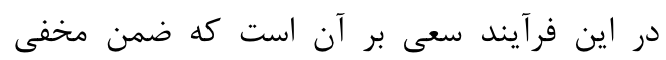

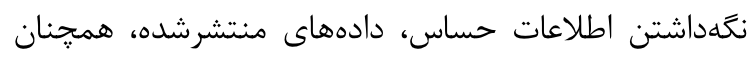
براى عمليات كشف دانش مفيد باقى بماند [3]. در ادامه،

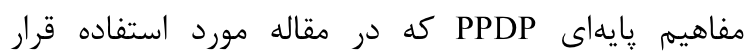
مى • مالكان ركورد: افرادى هستند كه اطلاعات مربوط به آنها در مجموعهداده ثبت شده است.

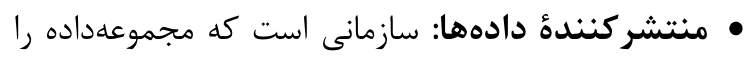

$$
\text { در اختيار دارد و اقدام به انتشار آن مى كند. }
$$

• مههاجمم: فرض بر اين است كه بعد از انتشار دادهها، مهاجم

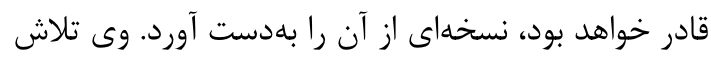

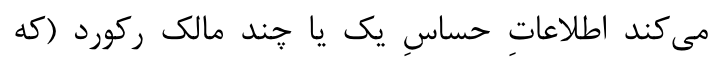
قربانى ناميده مىشوند) را از مجموعهداده استخراج كند.

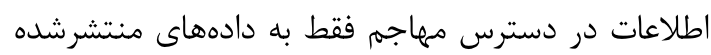
محدود نيست و امكان دارد از دانش ييشزمينهُ خود نيز

$$
\text { براى انجام حملات استفاده كند. }
$$

' Privacy-Preserving Data Publishing (PPDP) 
افراد مختلف، تفاوت وجود داشته باشد و موجب بهدستآمدن

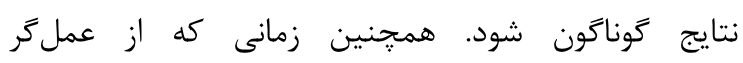
عمومىسازى سلولىه در يك مجموعهداده استفاده شود،

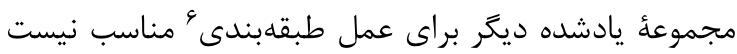

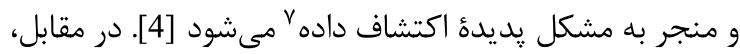
عملرَ فرونشانى، مقدار شبهشناسه موردنظر را با مقدار

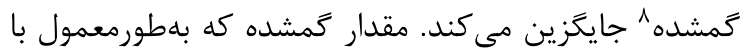
علامت "?" نمايش داده مىشود، بيان كر ناشناختهبودن مقدار صفت موردنظر است. استفاده از عمل كر فرونشانى بايد باد باد دقت انجام كيرد؛ زيرا تعداد زياد شبهشناسههايى كه مقدار كمششده

دارند، موجب كاهش كيفيت مجموعه داده مىشود [2].

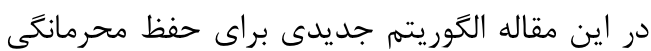

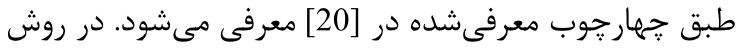
ي ييشنهادى از عمل مشكلات يادشده را براى عمومىسازى به همر اه نخواهد داشت.

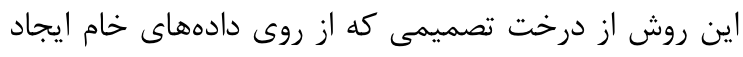

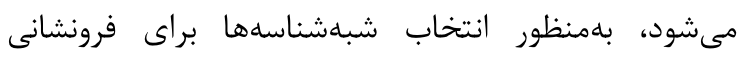
استفاده مى كند و مجموعلداده كمنامشده توسط آن براى عمل طبقهبندى مناسب است. نتايج بهدست آمده از آزمايشها نشان مى دهد كه دقت طبقهبندى در اين حالت، تفاوت اندكى با طبقهبندى روى مجموعه داده اوليه دارد. در ادامه ساختار مقاله بر اين اساس ارائه مىشود: درد درد بخش دوم بهاختصار رِيشينهٔ يزوهش درخصوص انتشار داده با

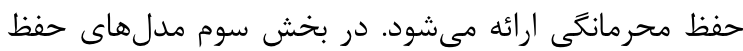

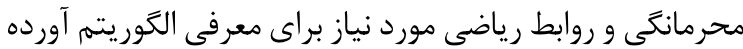
شده است. در بخش جهارم مقاله، الكوريته بِيشنهادى تشريح

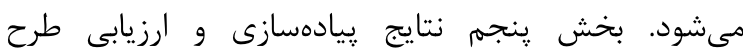

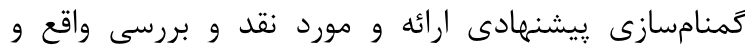
سرانجام در بخش ششم، مقاله جمعبندى و نتيجهكيرى

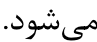

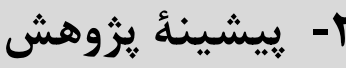

دستهاى از يزوهشهاى انجامشده در زمينه

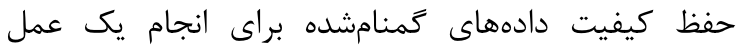
دادهاوى معين هستند. به بيان ديكر، تلاش مي شئود يرداز ركوردها بهكونهاى انجام كيرد كه مجموعهدادة كمنامشده

${ }^{\triangle}$ Cell Generalization

${ }^{4}$ Classification

${ }^{\vee}$ Data Exploration

${ }^{\wedge}$ Missing Value
هر دريافت كننده ممكن است، دادههاى مورد نياز خود را

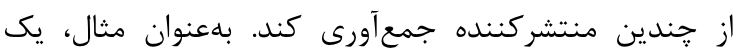

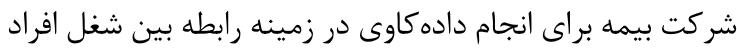

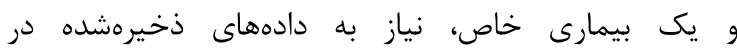

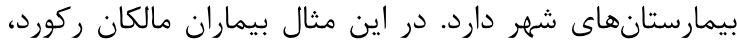

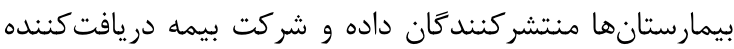

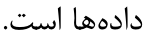

صفات ركوردها در يك مجموعهداده از لحاظ كاربرد در به جند دسته تقسيم مىشوند. به صفاتى كه مالك ركورد مايل نيست عموم از آنها اطلاع داشته باشند، صفت حساس كفته مىشود (مانند نوع بيمارى و يا ميزان حقوق يك إنى

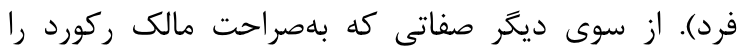

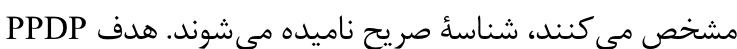
ينهانساختن تناظر بين شناسه صريح و صفت حساس ركوردها است. نخستين قدم در گمنامسازى مجموعه داده، حذف شناسههاى صريح از ركوردها است؛ اما همانطور كه در در درد [5] نشان داده شده است، حتى درصورت حذف شنف شناسٔ صريح بهكمى دستهاى ديخر از صفات كه شبهشناسه' ناميده مىشوند، مىتوان صفت حساس مالكان ركوردها را بلهدست

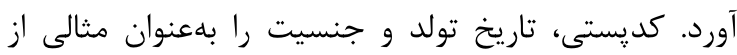
شبهشناسهها مى توان نام برد كه هر يك بهتئهايى براي تراى تعيين

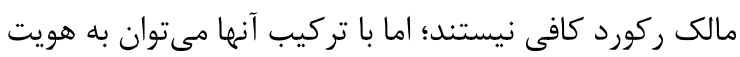

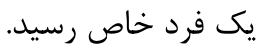
براى جلوگيرى از اين مشكل مىتوان با استفاده از

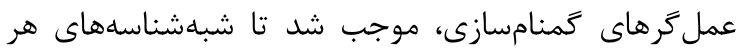

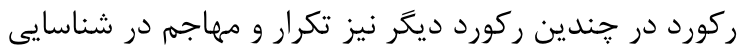

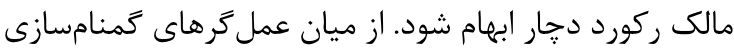

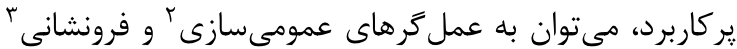

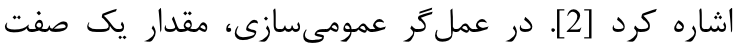

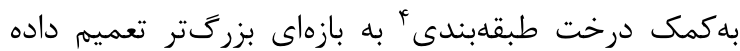
مىشود؛ براى مثال در صفت نشانى، مقدار ايران با خاورميانه

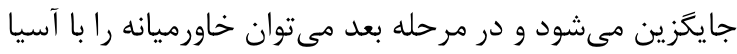

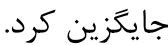
مشكل اين روش، نياز به تشكيل درخت طبقدبندى

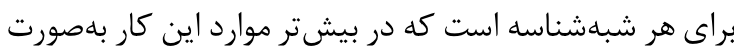
دستى و توسط يك فرد خبره انجام مى كيرد [3]. علاوهبراين ممكن است، بين درختهاى طبقهبندى تشكيلشده توسط

\footnotetext{
' Quasi Identifier

' Generalization

${ }^{r}$ Suppression

* Taxonomy Tree
} 


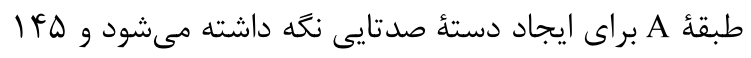

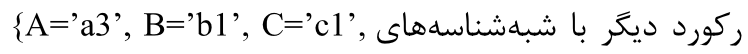
به مجموعه ركوردهاى گمنامشده اضافه مىشوند. D='d2'\} در قسمت ب، صفت E مورد بررسى قرار مى

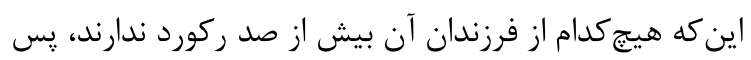

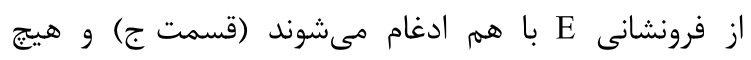
ركوردى به مجموعه ركوردهاى گمنامشده اضافه نمى شود. اين إنى روند تا ي يمايش كل درخت ادامه ميى بيابد. هرجند دقت طبقهبندى روى داده دهاى گَمنامشده

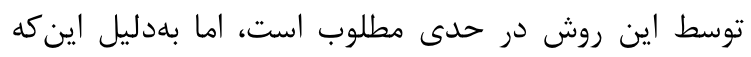

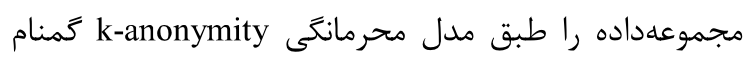
مى كند، ركوردهاى منتشرشده در مقابل حملاتى از قبيل مداده محرماني

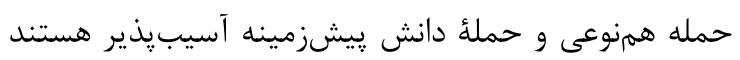

بهطوراصولى دست يابى به محرمانغى مطلق غير ممكن

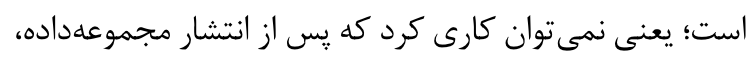

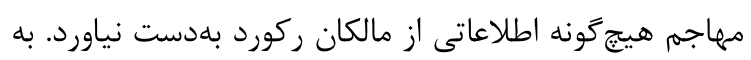

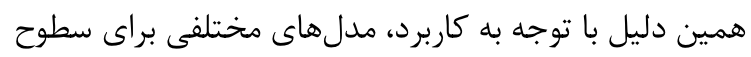

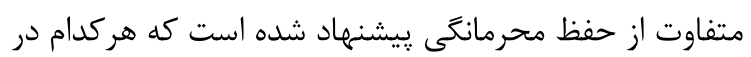
مقابله با حملات معينى كارآمد هستند. در جدو جدول مقايسهاى بين عملكرهاى گمنامى انجام گرفته است.

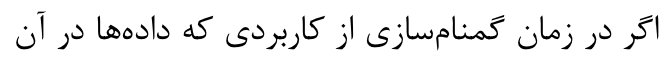

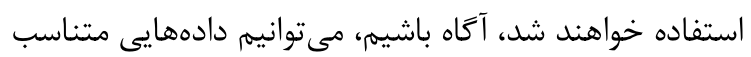

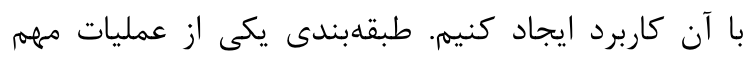
دادهاوى است. به همين دليل انتشار دادههايى كه كيفيت

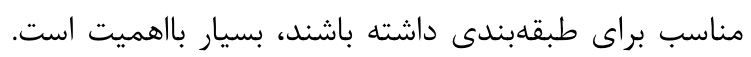

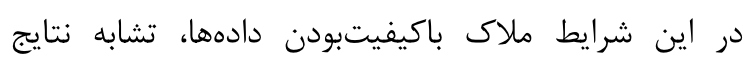
طبقهبندى روى دادههاى خام و گمنام است. در اين مقاله ضمن استفاده از ايده فرونهائ فرونشانى شباششناسههاى با بهره اطلاعاتى كمتر، به جاى كمنامسازى

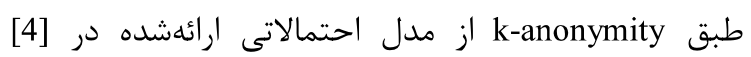

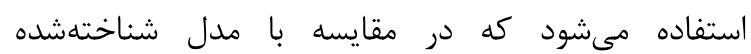
Differential privacy سودمندى و محرمانكى دادهها دست يافته است.

\section{ץ- مدلهاى حفظ محرمانتى در انتشار داده}

״يش از تلاش براى حفظ محرمانكى بايد مشخص كنيم جه انه

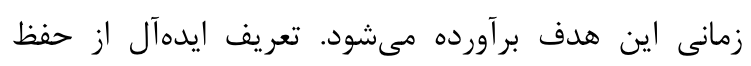

علاوهبر اينكه يك مدل حفظ محرمانگى را ارضا مى كند، براى

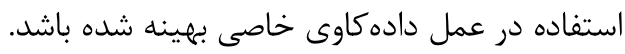

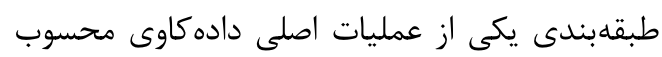

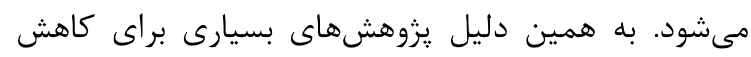

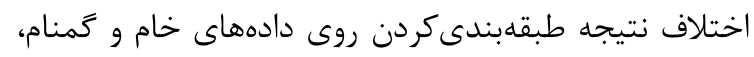

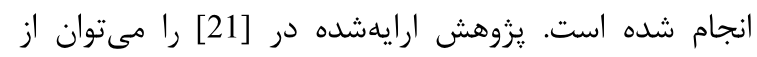
نخستين طرحهاى كاربردى در اين زمينه بهشمار آورد. اين روش براى هر عمل عمومىسازى G، ميزان محرمانكى كه بر له

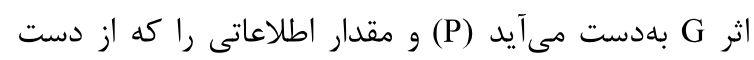

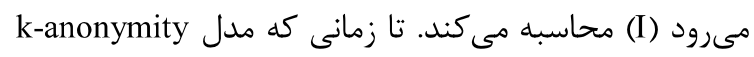
در كل مجموعهداده برقرار نشده است، عملى كه معيار كمينه كند، روى دادهها اعمال مىشود.

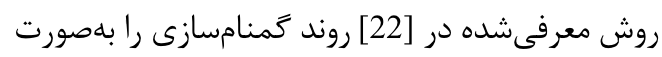

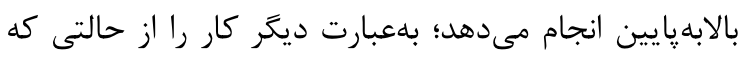
تمام شبهشناسهها در عمومىترين حالت خود قرار دارند، آغاز

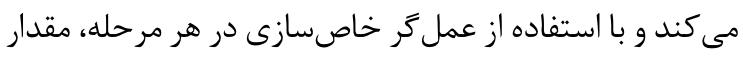

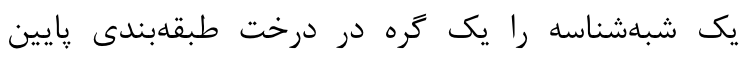

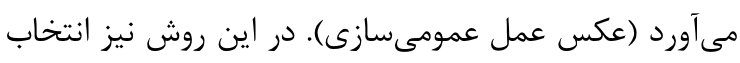

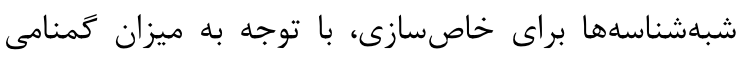

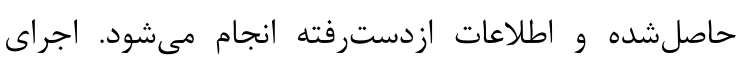

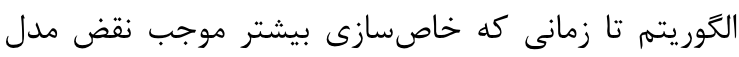

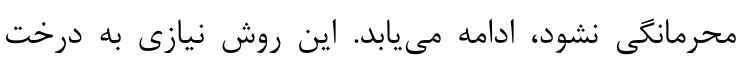

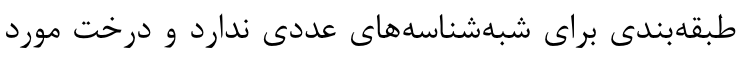

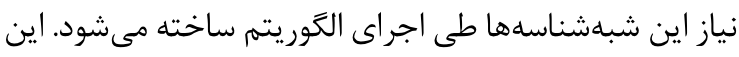
ايده در [10] بهبود بيشترى ييدا كرده است و مطابق آن اخر آن درخت طبقهبندى براى شبهشناسهاى موجود نباشد از عمل

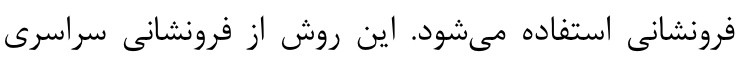

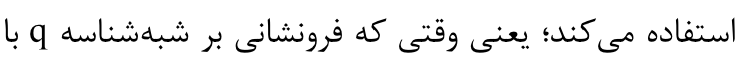
مقدار X اعمال مىشود، q در تمام ركوردهايى كه در آنها مقدار X دارد، فرونشانده مىشود.

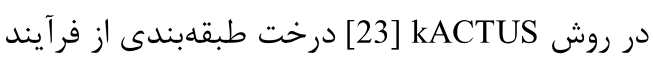
گمنامسازى حذف شده است و فقط از عمل استفاده مىشود. اين روش از فرونشانى محلى استفاده مى كند

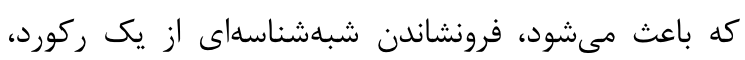

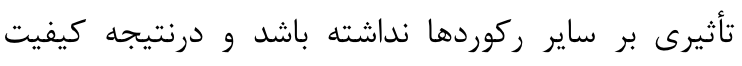
مجموعهداده كمتر كاهش ميىيابد. شكل (r) نحوه كاركرد اين

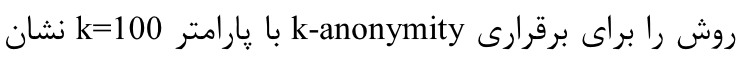
مى دهد. در قسمت الف، صفت D مورد يردازش قرار مى ئيرد.

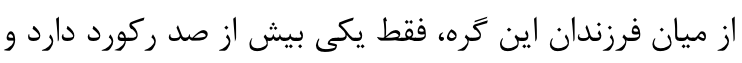

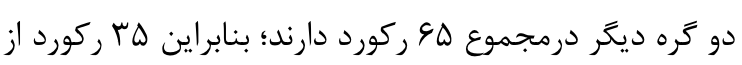




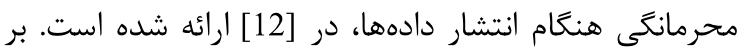

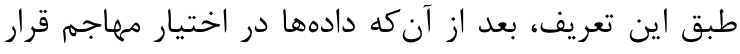
در حملات ويونددهى ركورد، مهاجم شبهشناسههاى قربانى راني مى كيرد، نسبت به زمانى كه دادهها را در اختيار نداشته است، با ركوردهاى انتشاريافته تطبيق مىدهد؛ بعد از انجام اين كار

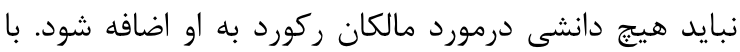
دستهاى كوجى از ركوردها باقى مىماند، كه ممكن است،

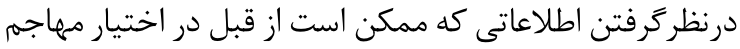

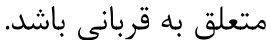

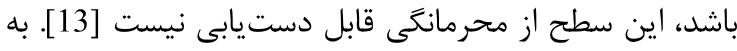
همين دليل در بيشتر كارهايى كه در حوزءٔ محرمانكى دادي داده

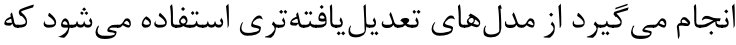
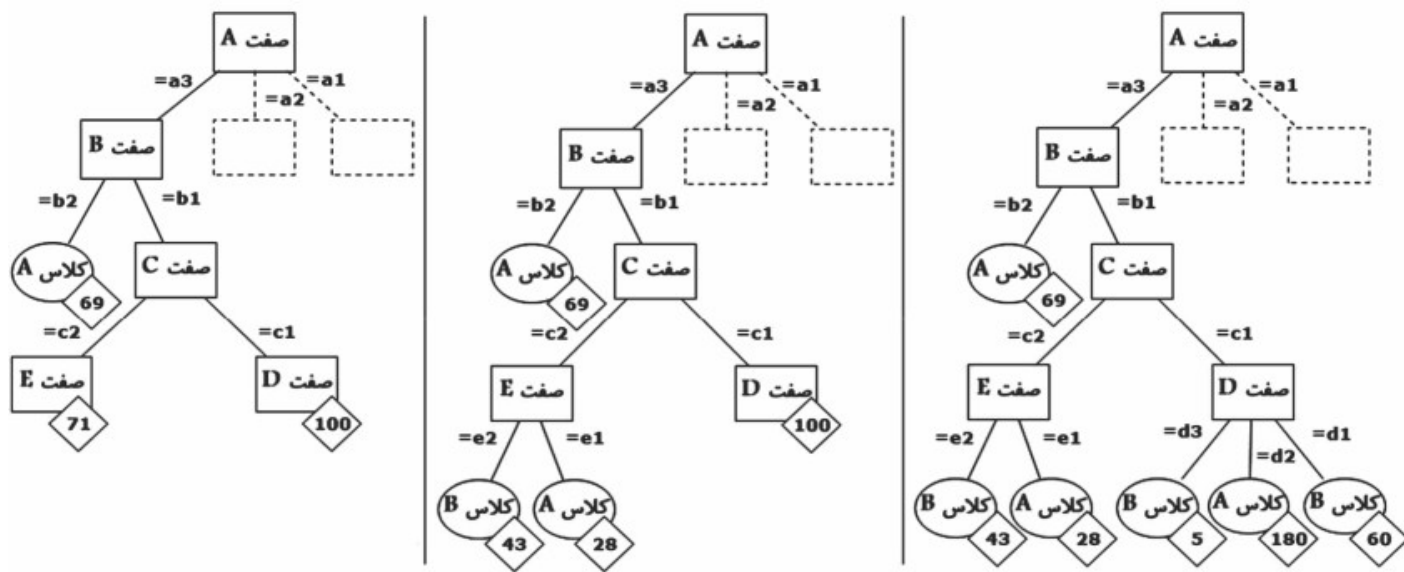

ج

$\varphi$

الف

(شكل - Y): روند اجراى الكوريتم kACTUS

(Figure-2): kACTUS Algorithm operation flow

(جدول - (1): مقايسه عملكر هاى كَمنامسازى

(Table-1): A comparison on anonymity operator

\begin{tabular}{|c|c|c|c|c|}
\hline مقدار صفات & قابليت استفاده از روش هاى & نمونه واقعى هستند؟ معرف يك؟ & 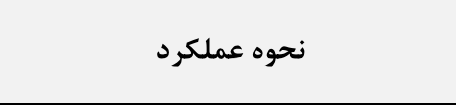 & 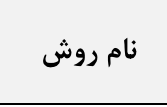 \\
\hline 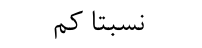 & بله & بله & تعميم مقدار صفت به بازهاى بزرگتر & عمومى سازى \\
\hline 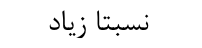 & بله & بله & حذف مقدار صفت & 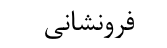 \\
\hline بدون تغيير & 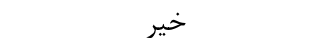 & تا حدودى & جدا كردن صفات حساس از شبهشناسهها & تجزيه \\
\hline بدون تغيير & بله & خير & جدا كردن صفات مرتبط به هم و تعويض آنها در ركوردهاى مختلف & برش دهى \\
\hline نسبتا كم & بله & خير & 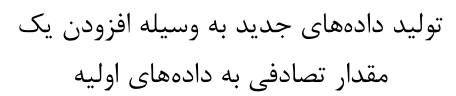 & ضافه كردن نوفه \\
\hline بلهور كامل عوض & بله & خير & 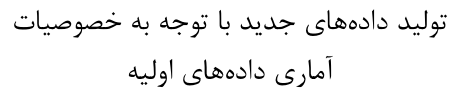 & توليد دادههاى \\
\hline
\end{tabular}

بدراحتى مىتواند آن را ييدا كند؛ زيرا تنها يك ركورد متناظر وجود دارد و درنتيجه حمله بيونددهى ركورد با موفقيت انجام إنيام

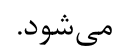

روش k-anonymity [5] براى جلوگيرى از جنين

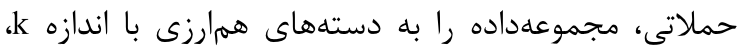

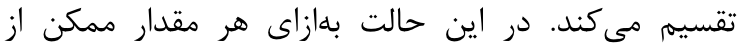

بيونددهى ركورد، زمانى رخ مى دهد كه مهاجم موفق

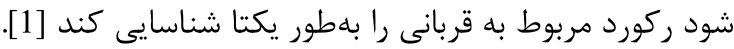

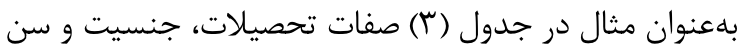
بهعنوان شبهشناسهها و حقوق بلعنوان صفت حساس درنظر كرفته شده است. پِ از انتشار اين جدول اكر مهاجم به دنه دنبال

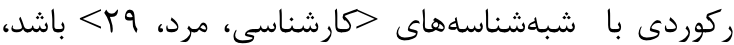




\section{r-r-r - مدل ييونددهى صفت}

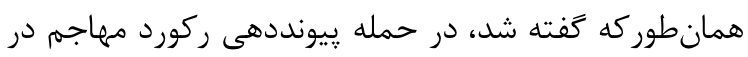

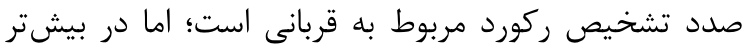

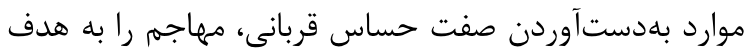

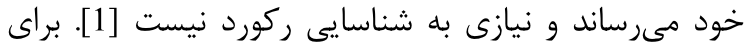

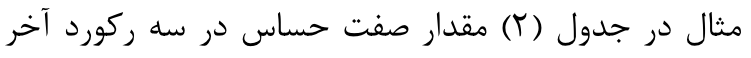

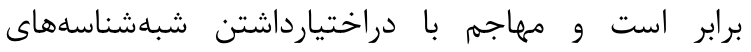

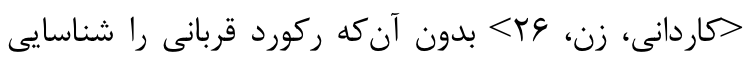

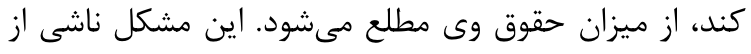

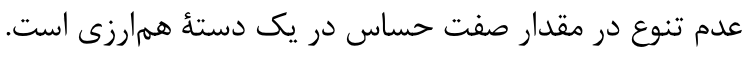
إنما 1-diversity

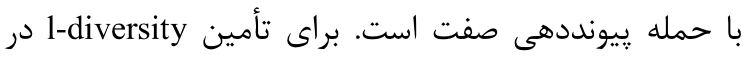

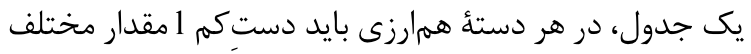

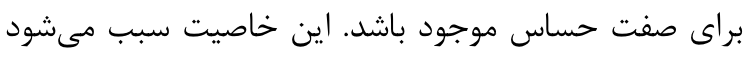

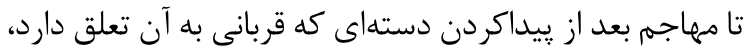

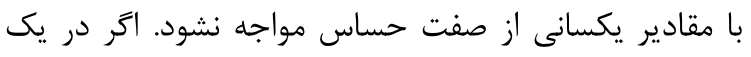

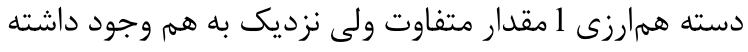

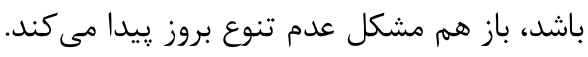

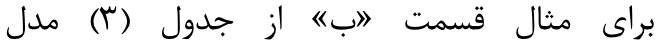
نختين كروه هماري 3-diversity

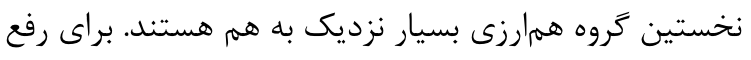

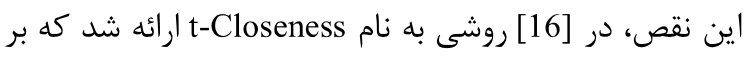

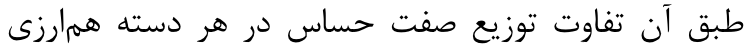

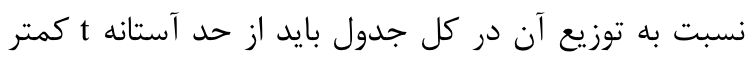

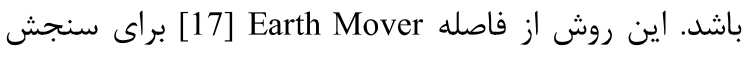

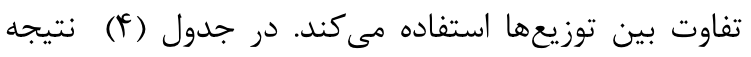

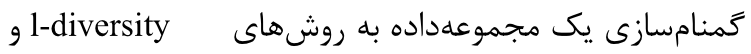
t-Closeness برقراركردن t-Closeness در يك جدائه

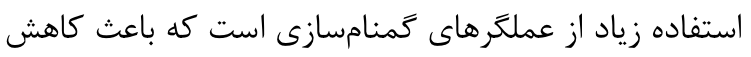

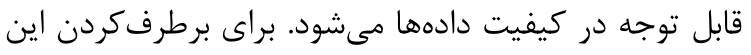

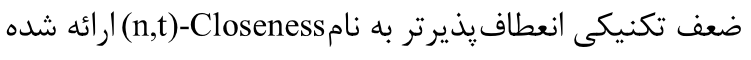

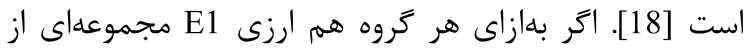
ركوردها با نام E2 موجود باشد كه: • بيش از n ركورد داشته باشد.

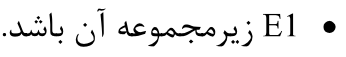

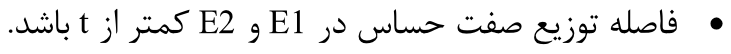

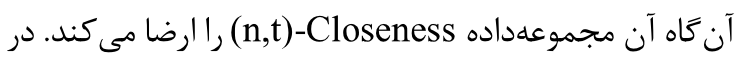
اين روش هرجه n كوجكتر درنظر كرفته شود، كيفيت دادهها كمتر لطمه مىبيند و در حالتى كه n برابر با تعداد كل

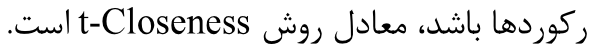

شبهشناسهها، يا هيج ركوردى در مجموعهداده وجود ندارد و

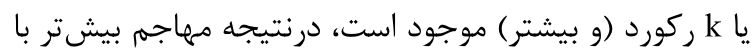

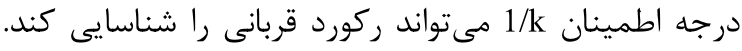

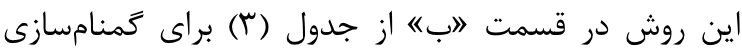

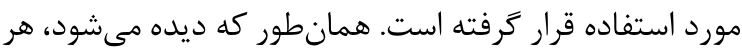

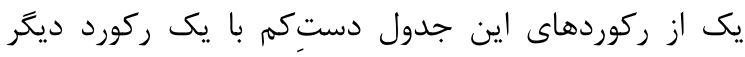

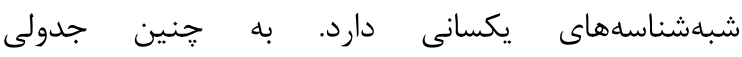
2-anonymous

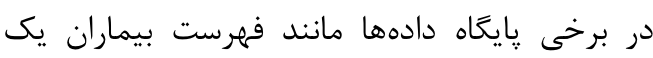

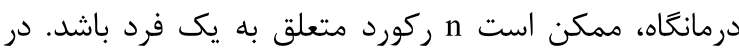

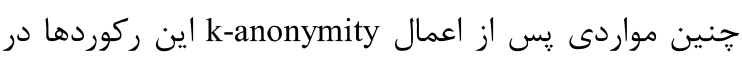

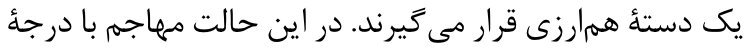

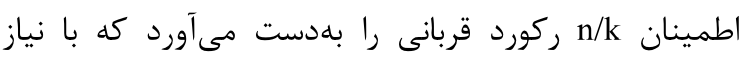
تعريفشده در k-anonymity مطابقت ندارد. براى حل اين اين

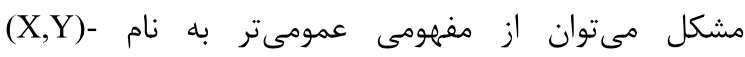

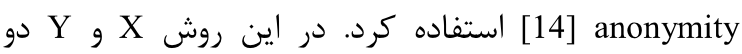

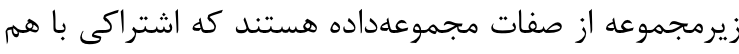

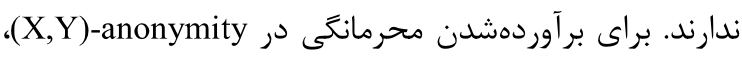

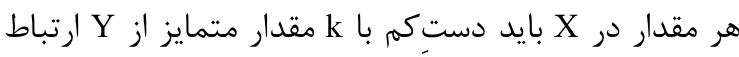

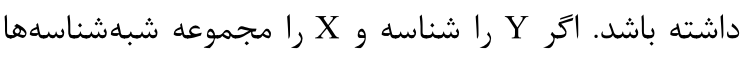

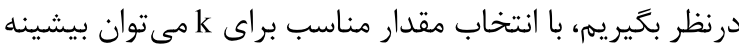

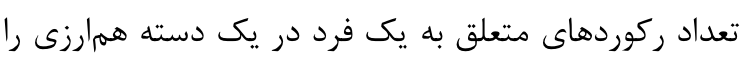
كنترل كرد. - (حد)

(جدول-Y): مثالى ازكمنام سازى k-anonymity با K(Table-2): A example of $k$-anonymity with $k=2$ الف) مجموعهداده خام

\begin{tabular}{|c|c|c|c|}
\hline حقوق & سن & جنسيت & تحصيلات \\
\hline $1 \cdots$ & TQ & 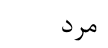 & كارشناسى ارشد \\
\hline $1 \cdot \Delta \cdot$ & r. & 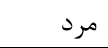 & كارشناسى \\
\hline $9 .$. & re & 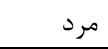 & كاردانى \\
\hline $11 \ldots$ & rA & 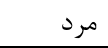 & دكترا \\
\hline 90 . & ra & زن & كارشناسى \\
\hline 90 . & $T V$ & زن & كارشناسى \\
\hline $9 \Delta$. & rq & زن & كاردانى \\
\hline
\end{tabular}
ب) جدول 2-anonymous

\begin{tabular}{|c|c|c|c|}
\hline حقوق & سن & جنسيت & تحصيلات \\
\hline $1 \cdots$ & {$[r \cdot-r \Delta)$} & مرد & ارشد و بالاتر \\
\hline $1 \cdot 0$. & {$[r \Delta-r \cdot)$} & مرد & يايينتر از ارشد \\
\hline $9 \ldots$ & {$[r \Delta-r \cdot)$} & مرد & يايينتر از ارشد \\
\hline $11 \cdots$ & {$[r \cdot-r \Delta)$} & مرد & ارشد و بالاتر \\
\hline $9 \Delta$. & {$[r \cdot-r \Delta)$} & زن & يايينتر از ارشد \\
\hline $9 \Delta$. & {$[r \cdot-r \Delta)$} & زن & يايينتر از ارشد \\
\hline $9 \Delta$. & {$[r \cdot-r \Delta)$} & زن & هايينتر از ارشد \\
\hline
\end{tabular}




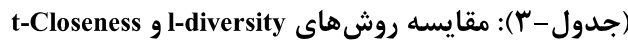

(Table-3): A comparison between I-diversity and t-closeness techniques

\begin{tabular}{|c|c|c|c|c|c|c|c|c|c|c|c|}
\hline \multicolumn{5}{|c|}{ پ) 0.167-closeness } & \multicolumn{3}{|c|}{ 3-diverse (ب } & \multicolumn{4}{|c|}{ الف) مجموعهداده خام } \\
\hline حقوق & سن & كديستى & & حقوق & سن & كديستى & & حقوق & سن & كديستى & \\
\hline$r \ldots$ & $\leq \varphi$. & FV९V* & 1 & $r \ldots$ & $r^{*}$ & $\varphi \vee \varepsilon^{* *}$ & 1 & $r \ldots$ & rq & FVGVV & 1 \\
\hline$\Delta \ldots$ & $\leq r$. & FYG & r & $f \ldots$ & $r^{*}$ & FVG** & r & $f \ldots$ & TY & FVG. r & $r$ \\
\hline$q \ldots$ & $\leq \varphi$ & FVG V* & $\wedge$ & $\Delta \cdots$ & $r^{*}$ & FVG** & r & $\Delta \ldots$ & $T V$ & FVGVA & $r$ \\
\hline $4 \ldots$ & $\geq r$. & \&vq.* & f & $9 .$. & $\geq F$. & $\varphi \vee q * *$ & f & $4 \ldots$ & Fr & Fva.d & f \\
\hline $11 \cdots$ & $\geq r$. & Fvq.* & $\Delta$ & $11 \ldots$ & $\geq F$. & fVq** & $\Delta$ & $11 \ldots$ & $\Delta r$ & $p \vee q . q$ & $\Delta$ \\
\hline$\wedge \cdots$ & $\geq F$. & Fvq.* & 9 & $\wedge \cdots$ & $\geq F$. & $F \vee q * *$ & 9 & $\wedge \ldots$ & iv & prq.q & 9 \\
\hline$f \ldots$ & $\leq r$. & fVG.* & r & $\gamma_{\cdots} \cdot$. & $\mu *$ & FyG** & v & $\gamma \ldots$ & $r$. & FVG. $\Delta$ & V \\
\hline$\gamma \ldots$ & $\leq r \cdot$ & fVG.* & V & $9 \ldots$ & r* & fVG** & $\Lambda$ & $9 \ldots$ & re & FVEVT & $\wedge$ \\
\hline $1 \ldots$ & $\leq \psi$. & FVG.* & 9 & $1 \ldots$ & $\mu^{*}$ & fVG** & 9 & $1 \ldots$ & r & FVG.V & 9 \\
\hline
\end{tabular}

جداول نسبت به مدل يِيونددهى ركورد و صفت، كارهاى

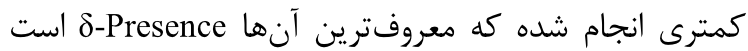

طبق اين مدل، احتمال شناسايى ركورد قربانى در

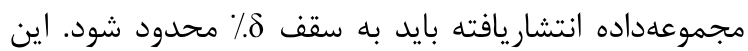

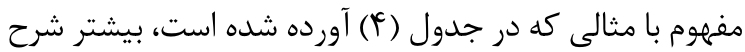

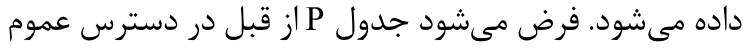

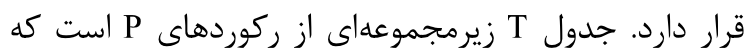

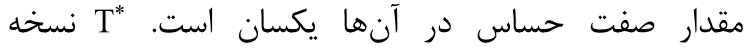

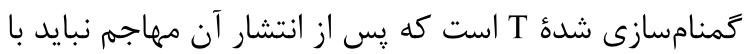

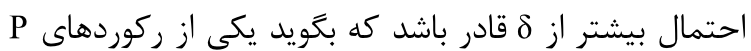

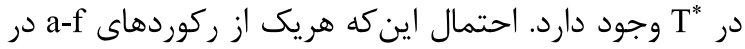

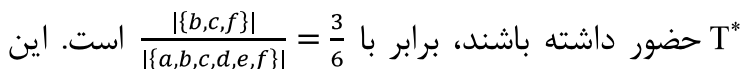

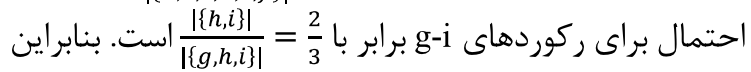

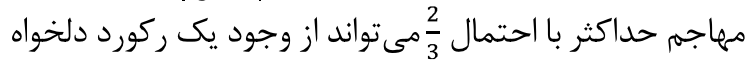
از P Pد جد اطمينان داشته باشد. همانطور كه كفته شد، در روش حداكثر ס٪ از وجود ركورد قربانى در جدول منتشرشده اطمينان دارد؛ بنابراين احتمال اين كه بتواند با موفقيت حمله

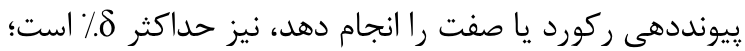

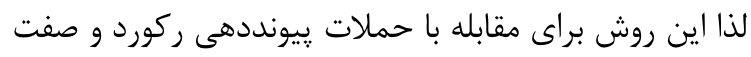
نيز كارايى دارد. عيب عمده روش در محاسبة احتمالات، فرض مىشود منتشركنندة داده و

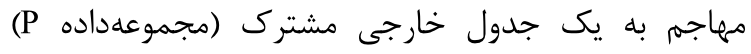
دسترسى دارند. درحالى كه جنين فرضى در دنياى واقعى زياد
(جدول-F-Presence روش):

(Table-4): $\delta$-Presence technique $\mathbf{P}$

\begin{tabular}{|c|c|c|c|c|}
\hline مليت & سن & كديستى & نام ل & \\
\hline ايالاتمتحده & ra & Fvq.q & Alice & $\mathrm{a}$ \\
\hline كانادا & $\Delta 9$ & prq.r & Bob & $\mathrm{b}$ \\
\hline ايالاتمتحده & Fr & $p \vee q . q$ & Chris & $\mathrm{c}$ \\
\hline برزيل & 11 & FVGT. & Dirk & $\mathrm{d}$ \\
\hline برزيل & tr & FVGT. & Eunice & e \\
\hline يرو - يرو & qr & FVAT & Frank & $\mathrm{f}$ \\
\hline اسيانيا & זr & FA१Vr & Gail & $\mathrm{g}$ \\
\hline بلغارستان & FV & FAqVT & Harry & $\mathrm{h}$ \\
\hline فرانسه & $\Delta T$ & 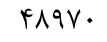 & Iris & $\mathrm{i}$ \\
\hline
\end{tabular}

\begin{tabular}{|c|c|c|c|}
\hline \multicolumn{4}{|c|}{$\mathrm{T}^{*}$} \\
\hline مليت & سن & كد يِستى & \\
\hline امريكا & * & $\mathrm{FV*}$ & $\mathrm{b}$ \\
\hline امريكا & * & p * & $\mathrm{c}$ \\
\hline امريكا & * & $f \gamma^{*}$ & $\mathrm{f}$ \\
\hline ارويا & * & $\varphi_{\wedge *}^{*}$ & $\mathrm{~h}$ \\
\hline ارويا & * & $\varphi \wedge^{*}$ & $\mathrm{i}$ \\
\hline
\end{tabular}

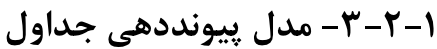
در برخى شرايط، صرف تشخيص اينكه ركورد قربانى در

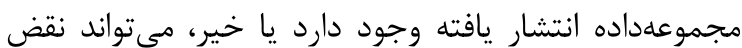
محرمانكى تلقى شود. بلعنوان نمونه زمانى كه يك بيمارستان

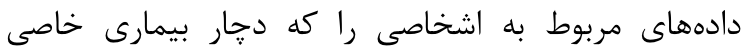
هستند، منتشر مى كند، يى بردن به هويت هر يك از افراد، نوع إصى

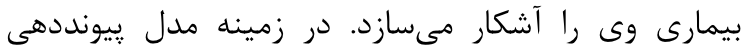


اطمينان مشاهدهشده ركورد r بهدست مى آيد.

ObservedConfidence $(r)=\beta \times \frac{\# S(r)}{|E(r)|}$

هرجه اطمينان مشاهدهده ركوردها كمتر باشد،

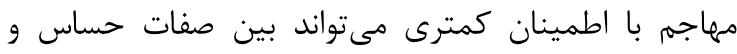

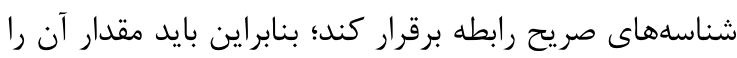
به سقف معينى محدود كرد. فرض مى شود مجموعهداده شامل

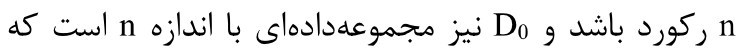
بهصورت تصادفى از فضاى نمونه ركوردها ايجاد شده است.

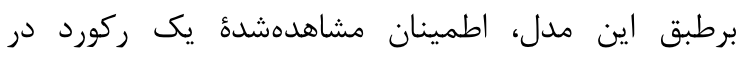

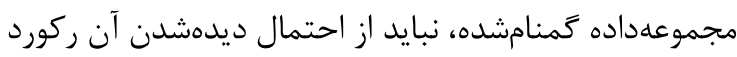
در Do بيشتر باشد. اين احتمال اطمينان مورد انتظار ناميده

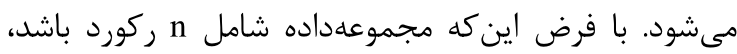

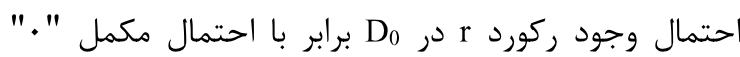

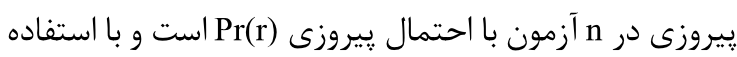

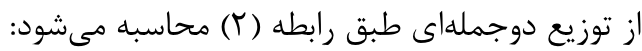

ExpectedConfidence $(r)=1-f(0 ; n, \operatorname{Pr}(r))$

$=1-\left(1-\operatorname{Pr}(r)^{2}\right)$

كه Pr(r) با فرض مستقلبودن صفات از يكديگر بلهوسيله ضرب احتمال شبهشناسهها در احتمال صفت حساس بهدست

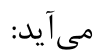

$\operatorname{Pr}(r)=\left(\prod_{i} \operatorname{Pr}\left(q_{i}\right)\right) \times \operatorname{Pr}(s)$

با توجه به رابطه (1) و (ז)، براى تأمين محرمانكى

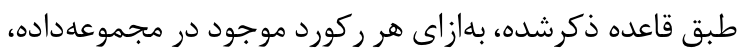
بايد رابطه (F) برقرار باشد:

ObservedConfidence $(\mathrm{r}) \leq$ ExpectedConfidence $(\mathrm{r})$

وقتى رابطه (f) براى ركوردى برقرار نبود، يكى از

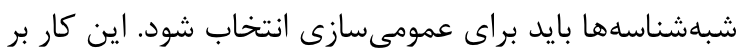

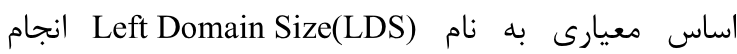
مى گيرد. LDS شبهشناسهاى با مقدار V، تعداد گرههايى است كه در درخت طبقهبندى در سطح برابر يا بالاتر از v قرار دارد.

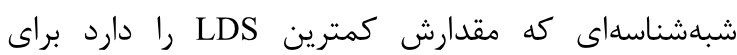
عمومى سازى بركزيده خواهد شد. در حين عمليات گمنامسازى، ممكن است، عمل عمومىسازى روى تعداد زيادى از شبهشناسههاى يك ركمين ركورد

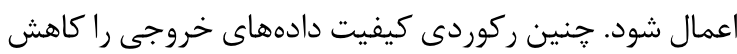
مىدهد. به همين منظور از معيار تخريب براى سنجش مين ميزان

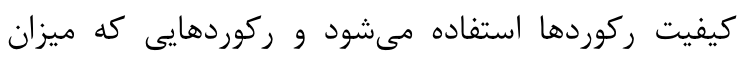

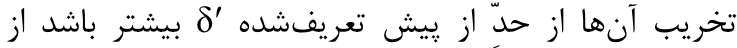

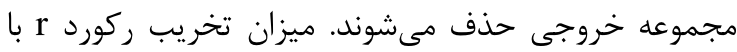

r-r-r-r

در مدلهاى احتمالاتى هدف جلوگيرى از ييونددهى ركورد

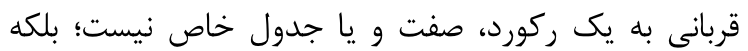

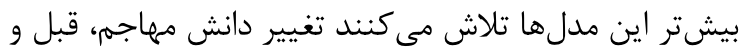

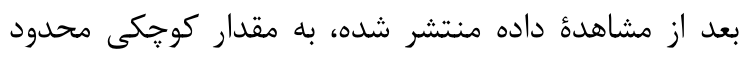
شود. طرح ارائهشده در [13] يكى از سختگيرانهترين

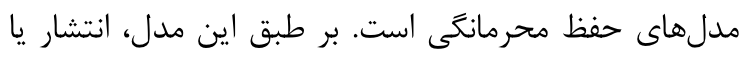

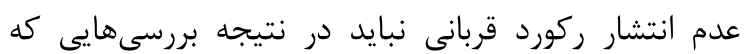

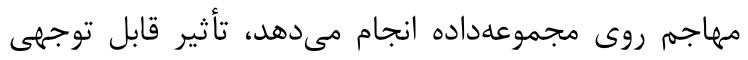

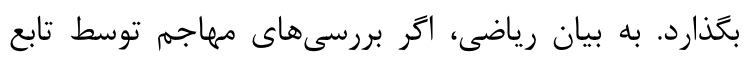

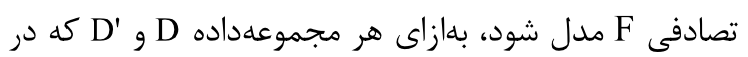
وجود يك ركورد اختلاف دارند، بايد رابطه زير برقرار باشد: $\forall S \in \operatorname{Range}(F)\left(\operatorname{Pr}[\mathrm{F}(\mathrm{D})=\mathrm{S}] \leq e^{\varepsilon} \times \operatorname{Pr}\left[\mathrm{F}\left(\mathrm{D}^{\prime}\right)=\mathrm{S}\right]\right)$ كه S صفت حساس و ع پارامترى است كه هرجه كوجكتر انتخاب شود، ميزان تأثير يك ركورد بر نتيجه بررسى عها كمتر

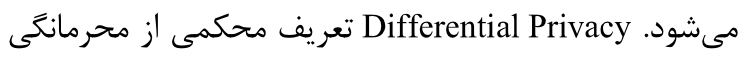
ارائه مىدهد كه تفاوتى ميان صفات حساس و ساير صفات

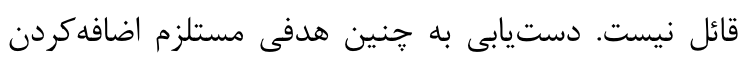

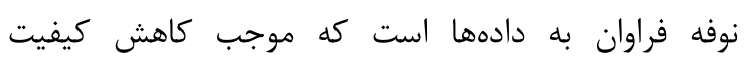
مجموعهداده مىشود. طرح ارايهشده در [20] با درنظرداشتن اين مشكل مدلى تعديليافتهتر معرفى كرده است: اطمينانى

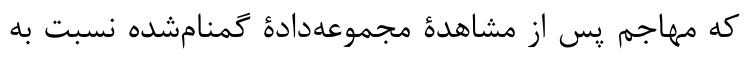

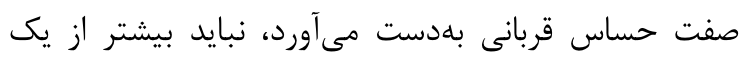
حدس تصادفى باشد. ازآنجاكه طرح ارائهشده در اين مقاله بر بردي

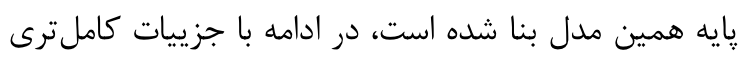
تشريح مىشود. مدل حفظ محرمانگى معرفى مدى لشود در [AGF) [20) بر

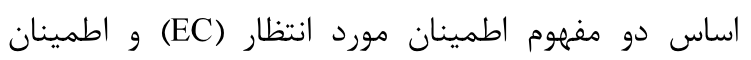

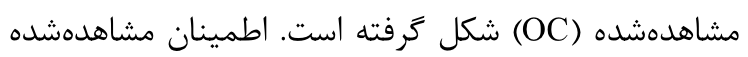

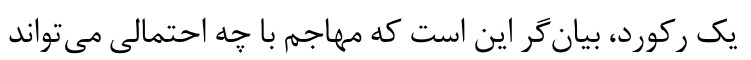
صفت حساس آن را به قربانى نسبت دهد. اخر ركورد قربانى عضو دسته همارزى بهاندازه | (v(v) باشد و و تعداد تكرار

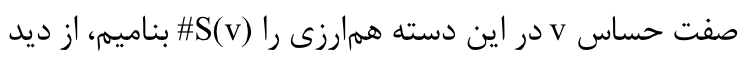

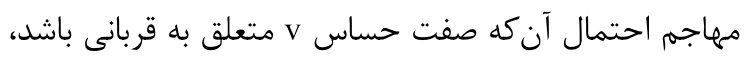

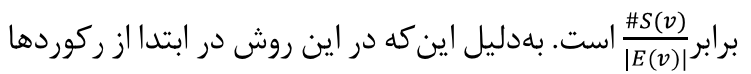

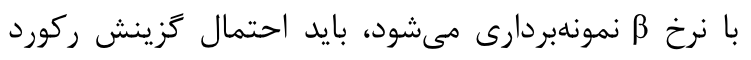

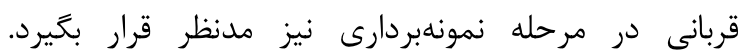

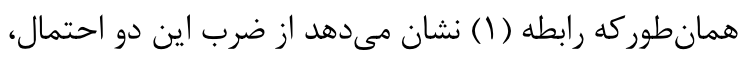


تخريب "ا" به معنى عمومىسازى تمام شبهشناسهها تا گره

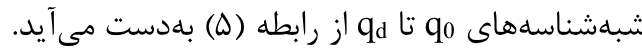

در جدول (ه) مدلهاى مطرح محرمانگى بر اساس

ريشه است.

ويزگى ها و نقاط ضعف هركدام مقايسه شدهاند.

$\delta=\frac{1}{d} \sum_{i=1}^{d}\left(1-\frac{\text { Currentlevel of } \mathrm{q}^{\prime} i}{\text { Maximal level in } q_{i}}\right)$

اگر تخريب "." باشد به معنى اين است كه تمام

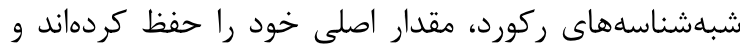

(جدول - (ه): مقايسه مدل هاى حفظ محرمانكى

(Table-5): A Comparison between Privacy models

\begin{tabular}{|c|c|c|c|}
\hline نقطه ضعف & ويثزى ها & رابطهاى كه در مجموعهداده بايد برقرار شود & نام مدل \\
\hline جند ركورد از يك فرد در يك دسته & محافظت در برابر ييونددهى ركورد، & kرومبندى ركوردها در دستههاى هم ارزى به اندازه & k-anonymity \\
\hline 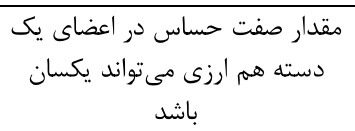 & k- رفع ضعف ذكر شده براى & 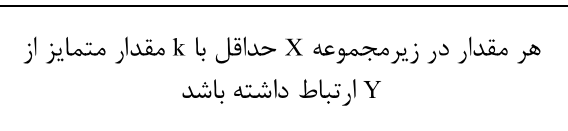 & $\begin{array}{l}(\mathrm{X}, \mathrm{Y})- \\
\text { anonymity }\end{array}$ \\
\hline 1 مقدار متنوع مىتوانند نزديك به & محافظت در برابر ييونددهى صفت، & وجود 1 مقدار متنوع از صفت حساس در هر دسته & 1-diversity \\
\hline تخريب زياد & 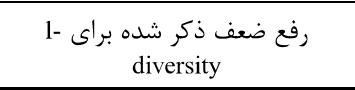 & تفاوت توزيع صفت حساس در هر دسته همارزى نسبت آن در كل جدول أ كمتر باشد & t-closeness \\
\hline 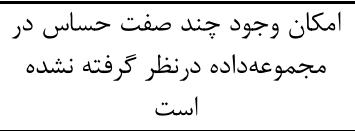 & t- رفع ضعف ذكر شده براى $\begin{array}{l}\text { toseness } \\
\text { clos }\end{array}$ & 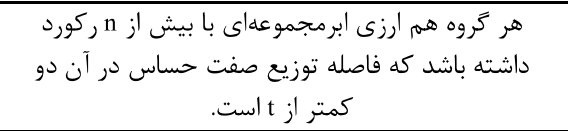 & $(\mathrm{n}, \mathrm{t})$-closeness \\
\hline 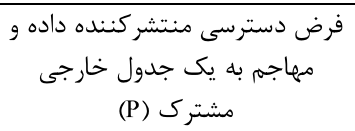 & محافظت در برابر يِيونددهى ركورد، & احتمال وجود ركورد قربانى در مجموعهداده انتشار يافته & $\delta$-presence \\
\hline تخريب زياد & نزيكترين مدل به تعريف ايدهآل & 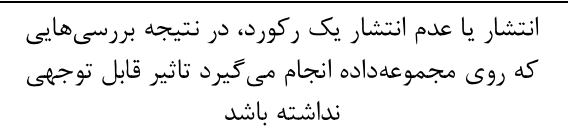 & $\begin{array}{l}\text { differential } \\
\text { privacy }\end{array}$ \\
\hline فرض مستقل بودن مقدار صفات & $\begin{array}{l}\text { رفع ضعف ذكر شده براى } \\
\text { differential privacy }\end{array}$ & اطمينان مشاهده شده ركوردها كوجكتر از اطمينان مورد & AGF \\
\hline
\end{tabular}

براى گمنامسازى استفاده مى كند، در نحوه طبقهبندى ركوردهاى خروجى ابهام بلوجود مى آيد [1]. بهعنوان نمونه

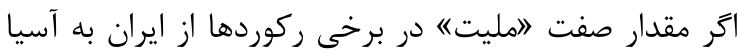

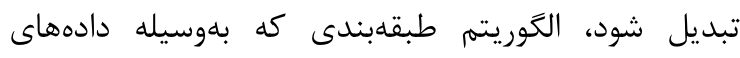

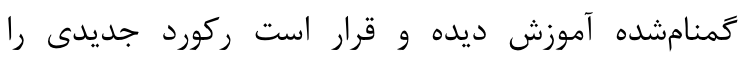
طبقهبندى كند، بايد از رابطه آسيا و ايران اطلاع داشته باشد؛ دمراء زيرا در دادهاى واقعى صفت مليت هيجزاه مقدار آسيا ندارد.

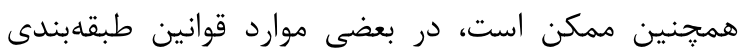

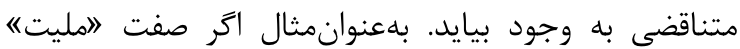
مقدار ايران داشت، آن ركورد متعلق به طبقهُ يك، و اكر مقدار آسيا داشت، متعلق به طبقهُ دو است.

در روش زيشنهادى از عمل مىشود؛ در نتيجه مشكلات ذكرشده براى عمومىسازى را بـ ريه همراه نخواهد داشت. در اين روش، انتخاب شبهشناسهها براى فرونشانى بلوسيله درخت تصميمى كه از روى دادههاى خام ايجاد مىشود، صورت مىيذيرد.

\section{ץ- طرح الكوريتم ييشنههادى}

در اين بخش از مقاله، الكوريتم جديدى براى حفظ محرمانكى

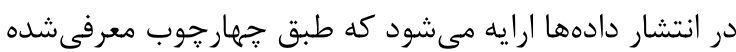

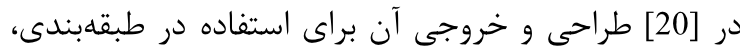

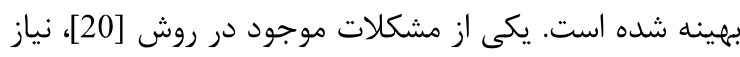

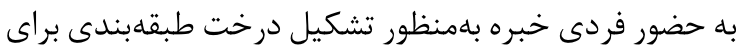

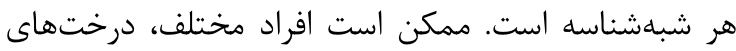

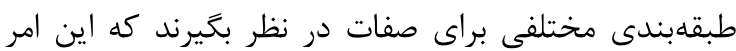
موجب بلهدتآمدن نتايج گَوناگون مىشود. علاوهبراين

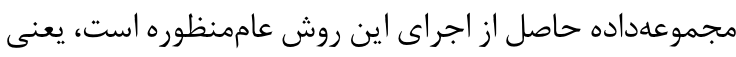
در كاربردهاى مختلف دادهكاوى مىتوان از آن استفاده كرد؛ ولى براى استفاده در كاربرد خاصى بهينه نيست. هنگًامى كه دادهها با هدف استفاده در طبقهبندى منتشر مىشوند،

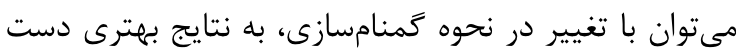
يافت.

بهدليل اينكه [20] از عمل 
شبهشناسه A در تعيين طبقأ اين ركورد نقشى ندارد، بنابراين

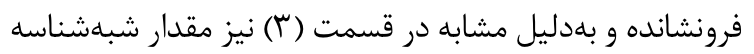
C حذف مىشود. بعد از اينكه تمام ركوردها يك دور بردازش شدر شدند، در

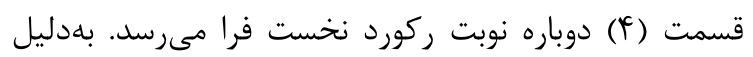

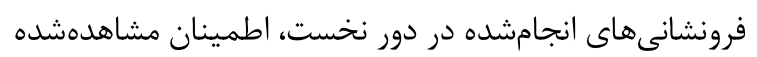

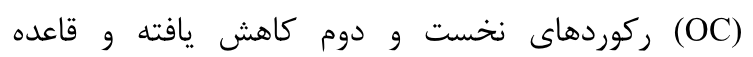

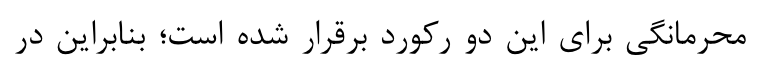

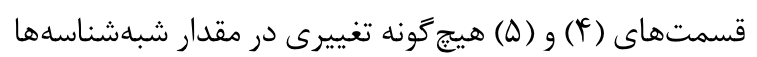

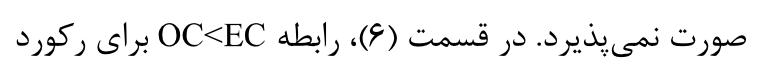

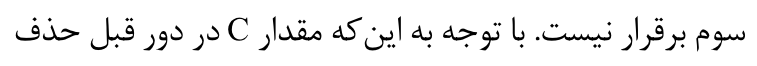

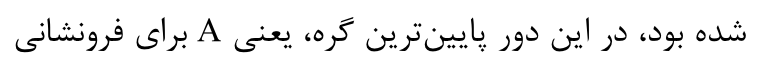

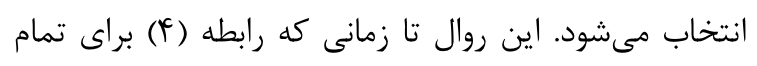
ركوردها برقرار شود، ادامه مى يابد.

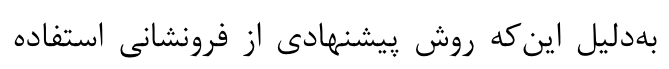

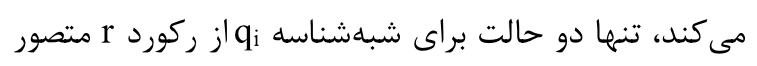

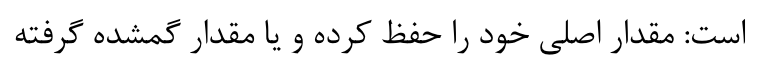

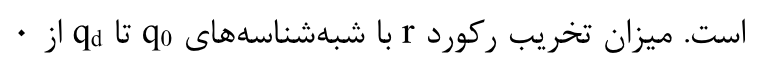
بdدست مى آيد. $\delta=\frac{1}{d} \sum_{i=1}^{d} g\left(r, q_{i}\right), g\left(r, q_{i}\right)=$ $\left\{0: q_{i}\right.$ isn't missed from $r$

\{1: $q_{i}$ is missed from $r$
(2) OC $>$ EC

\begin{tabular}{|l||ccr|}
\hline & A & B & C \\
\hline 1 & a2 & b1 & $?$ \\
\hline 2 & d1 & b3 & c1 \\
\hline 3 & a1 & b1 & c2 \\
\hline$\vdots$ & $\vdots$ & $\vdots$ & $\vdots$ \\
\hline
\end{tabular}

(3)

\begin{tabular}{|cccr|}
\hline & $\mathrm{A}$ & $\mathrm{B}$ & $\mathrm{C}$ \\
\hline 1 & $\mathrm{a} 2$ & $\mathrm{~b} 1$ & $?$ \\
\hline 2 & $?$ & $\mathrm{~b} 3$ & $\mathrm{c} 1$ \\
\hline 3 & $\mathrm{a} 1$ & $\mathrm{~b} 1$ & $\mathrm{b2}$ \\
\hline$\vdots$ & $\vdots$ & $\vdots$ & $\vdots$ \\
\hline
\end{tabular}
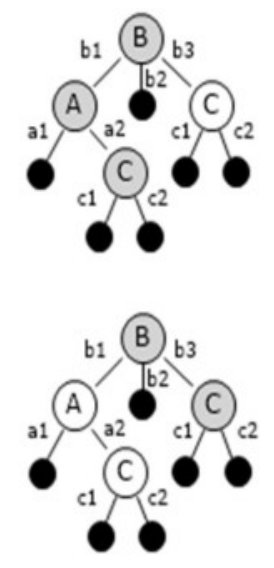

\begin{tabular}{l|l||crr|}
\cline { 2 - 4 } \multicolumn{1}{c}{$(4)$} & & A & B & C \\
\cline { 2 - 5 }$O C<E C$ & 1 & a2 & b1 & $?$ \\
\cline { 2 - 5 } & 2 & $?$ & b3 & C1 \\
\hline \multirow{yyy}{*}{3} & a1 & b1 & $?$ \\
\hline$\vdots$ & & $\vdots$ & $\vdots$ \\
\hline
\end{tabular}

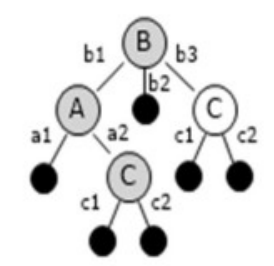

(5)

\begin{tabular}{|l|l|crr|}
\cline { 2 - 4 } $\mathrm{O} O C<E C$ & 1 & a2 & b1 & $?$ \\
\cline { 2 - 5 } & 2 & $?$ & $\mathrm{~b} 3$ & $\mathrm{c} 1$ \\
\cline { 2 - 5 } & 3 & $\mathrm{a} 1$ & $\mathrm{~b} 1$ & $?$ \\
\hline \multirow{y}{*}{$\vdots$} & & $\vdots$ & $\vdots$ & $\vdots$ \\
\hline
\end{tabular}
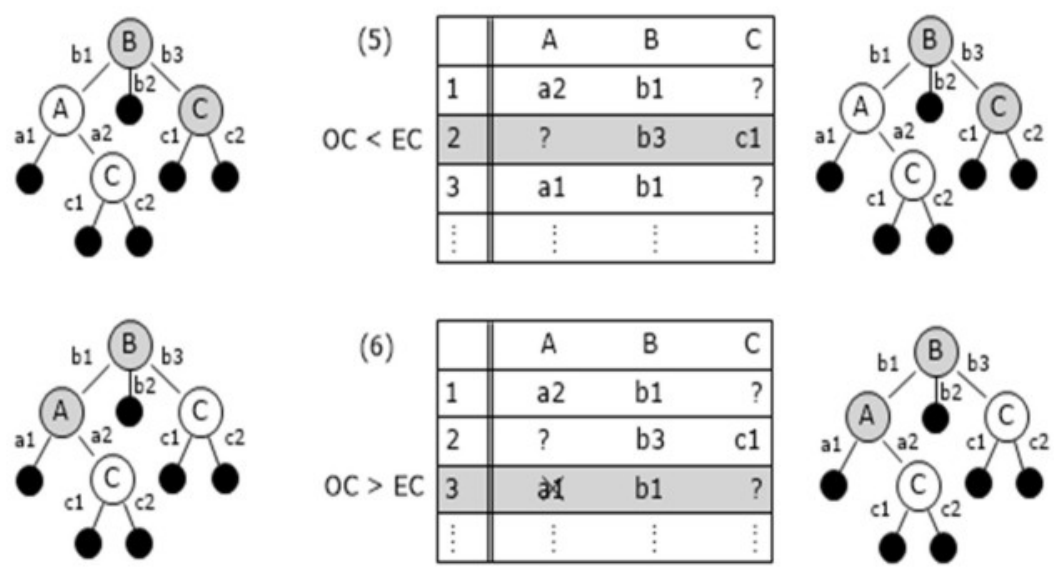

\begin{tabular}{c|l||crr|}
\cline { 2 - 5 }$(6)$ & & $\mathrm{A}$ & $\mathrm{B}$ & $\mathrm{C}$ \\
\cline { 2 - 5 } $\mathrm{N}$ & $\mathrm{y}$ & $\mathrm{a} 2$ & $\mathrm{~b} 1$ & $?$ \\
\cline { 2 - 5 } & 2 & $?$ & $\mathrm{~b} 3$ & $\mathrm{C} 1$ \\
\cline { 2 - 5 } & 3 & $\mathrm{~d} 1$ & $\mathrm{~b} 1$ & $?$ \\
\cline { 2 - 5 } & $\vdots$ & $\vdots$ & $\vdots$ & $\vdots$ \\
\hline
\end{tabular}

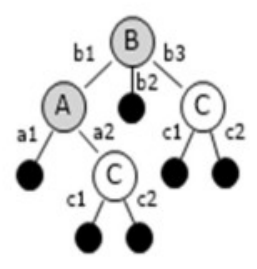

در روش ريشنهادى، انتخاب شبهشناسهها براى فرونشانى، بلوسيله درخت تصميم انجام مىشود و در در اين كار

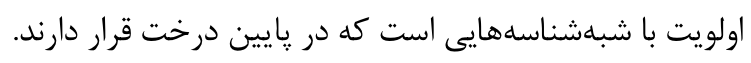

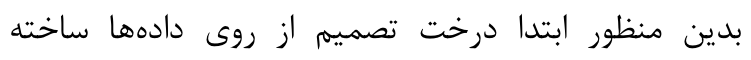
مىشود؛ سيس اطمينان مشاهدهشده و اطمينان مورد انتظار براى هر يك از ركوردها محاسبه شده و برقراربودن رابطه (f)

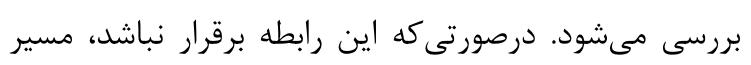

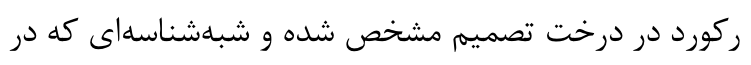

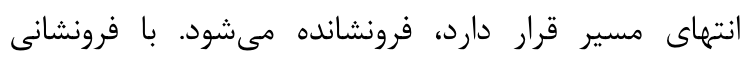

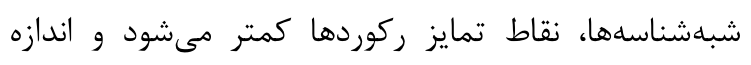

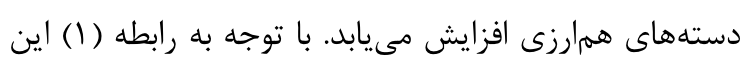

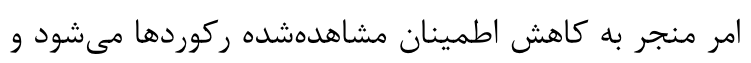

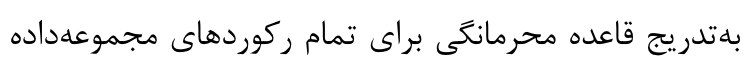
برقرار مىشود.

در شكل (ب) مثالى ساده از نحوه كاركرد روش

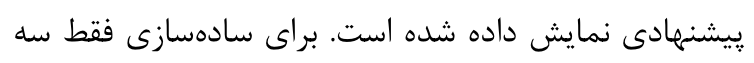

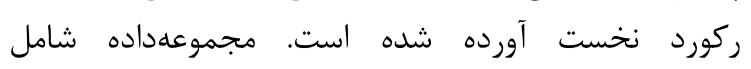

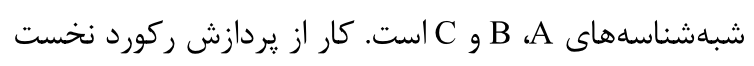

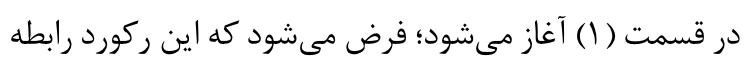

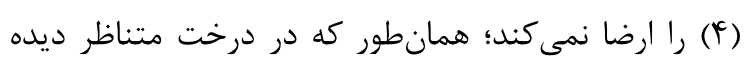

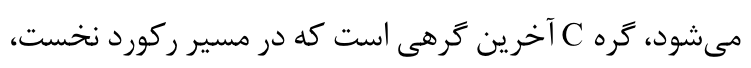

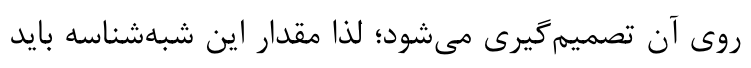
حذف شود. رابطه OC<

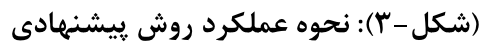

(Figure-3): Operation of the proposed technique 
اگر ركورد r هنوز رابطه (Y) را ارضا نمى كند، بايد عمل گر فرونشانى روى يكى از شبهشناسههاى آن اعمال شود. مرحله نه با استفاده از درخت تصميم DT از ميان شبهشناسهها، صفت q كه كمترين بهره اطلاعاتى را دارد، انتخاب مى كند. نحوه اين كار در الكوريتم ارايهشده در شكل (D) شرح داده مىشود. مرحله ده فرونشانى را روى شبهشناسه

$$
\text { q از رورد r اعمال مي كند. }
$$

مرحلئ دوازده ميزان تخريب ركورد را از طريق •صفر

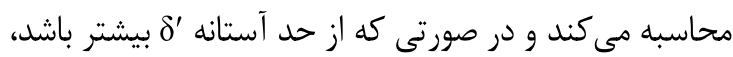
ركورد مربوطه از مجموعه D* حذف مىشود. مرحلئ نوزده

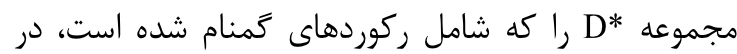

$$
\text { خروجى قرار مى مهد. }
$$

نحوه انتخاب صفتى كه بايد فرونشانده شود در شكل

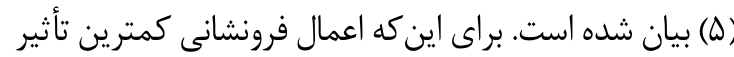

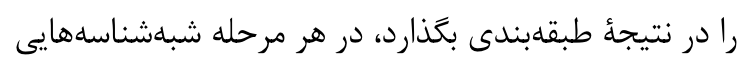
كه دورتر از ريشه درخت طبقهبندى هستند، فرونشانده مىشوند. ورودىهاى الكوريتم ركورد rr، مجموعه شبهشناسهها

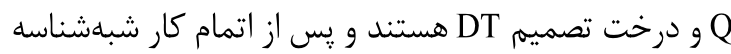
qi

\section{QIWithLowestInfoGain(r, Q, DT)}

Output: qi

$$
\begin{aligned}
& \text { 1: } \mathrm{qi} \leftarrow \mathrm{Q}[0] \\
& \text { 2: CQ } \leftarrow \emptyset \\
& \text { 3: FOR each a } \in \text { Q DO }
\end{aligned}
$$

4: IF a is not missed from $r$ THEN

5: $\mathrm{CQ} \leftarrow \mathrm{CQ} \cup\{\mathrm{a}\}$

\section{6: END IF}

7: END FOR

8: $\mathrm{n} \leftarrow \operatorname{Root}(\mathrm{DT})$

9: WHILE $\mathrm{n} \notin$ Leaves(DT) DO

10: IF $n \in$ CQ THEN

$$
\text { 11: } \quad \text { qi } \leftarrow \mathrm{n}
$$$$
\text { 12: } \quad \mathrm{CQ} \leftarrow \mathrm{CQ}-\{\mathrm{n}\}
$$

13: END IF

14: $\mathrm{n} \leftarrow \operatorname{NextNode}(\mathrm{DT}, \mathrm{n}, \mathrm{r})$

15: END WHILE

16: IF $\mid$ CQ $\mid>0$ THEN

17: $\quad$ qi $\leftarrow$ RandomSelect(CQ)

18: END IF

19: RETURN qi

(شكل - (ه): انتخاب يك شبهشناسه براى فرونشانى

(Figure-5): Selection of a quasi identifier for Suppression
الكوريتم ارايهشده در شكل (f) روند گمنامسازى

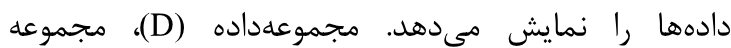
شبهشناسهها (Q)، احتمال مقادير مختلف براى هر شبهشناسه

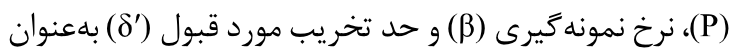
ورودى به الكوريتم داده مىشود و با اجراى الكوريتم مجموعهداده گمنام شده (D) ايجاد مىشود. مرحله يك

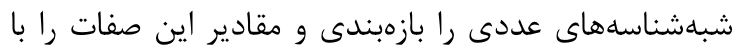

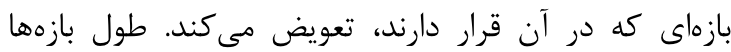

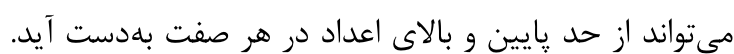
اين كار بلهنظور كمترساختن يراكندگى مقادير در صفات

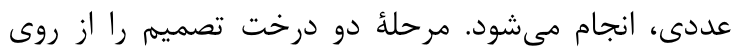

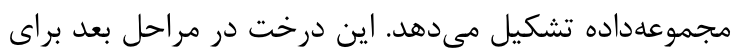

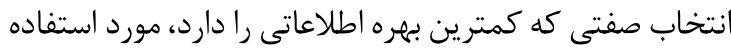

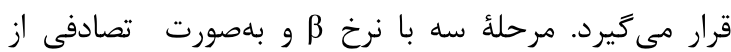
مجموعهداده نمونهبردارى مى كند. ميرد.

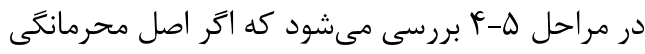

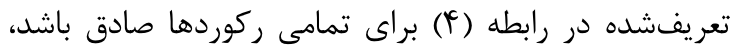

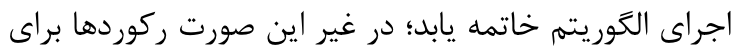

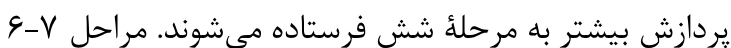

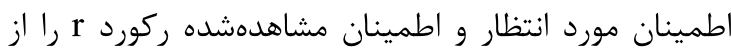
رابطه (1) و رابطه (Y) محاسبه ميى كنند.

\section{Anonymize (D, Q, $\left.P, \beta, \delta^{\prime}\right)$}

\section{Output: D*}

1: $\mathrm{D}^{*} \leftarrow$ DiscretizeNumericQIs(D, Q)

2: DT $\leftarrow$ GenerateDecisionTree $\left(D^{*}\right)$

$3: D^{*} \leftarrow$ RandomSample $\left(D^{*}, \beta\right)$

4: WHILE all records in $D^{*}$ does not satisfy Eq. 3-4 DO

5: $\quad$ FOR each $r \in D^{*}$ DO

6: ec $\leftarrow$ ExpectedConfidence $\left(r, D^{*}, Q, P\right)$

7: oc $\leftarrow$ ObservedConfidence $\left(r, D^{*}, Q\right)$

8: IF ec $<$ oc THEN

9: $\quad \mathrm{q} \leftarrow$ QIWithLowestInfoGain(r, Q, DT)

10: $\quad \mathrm{r} \leftarrow$ Suppress $(\mathrm{r}, \mathrm{q})$

11: ELSE

12: $\quad \delta=$ Distortion( $(\mathrm{r}, \mathrm{Q})$

13: $\quad$ IF $\delta>\delta$, THEN

14: $\quad D^{*} \leftarrow D^{*}-r$

15: $\quad$ END IF

16: END IF

17: END FOR

18: END WHILE

19: RETURN D*
(شكل - (F): روند כمنامسازى دادهها

(Figure-4): Annonymizaton technique 
كرفته مىشود. لازم به ذكر است كه خواندن دادهها از

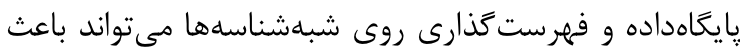
بهبود سرعت اجراى الكوريتم شود. فايل كمنامسازىشده بهصورت arff. \}نام الكوريته كمنامسازى \{. كنام مجموعهاده

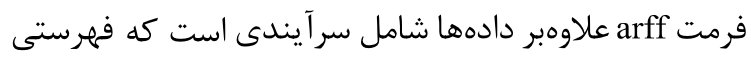
از نام و نوع صفات در آن نكَهدارى مى شيود.

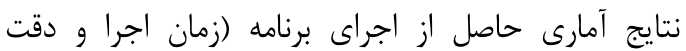

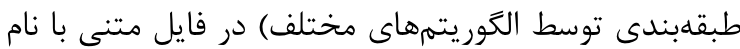

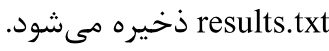

\section{|-1 - ارزيابى و نتايج بهدست آمده}

در اين بخش به بررسى روش پيشنهادى (PM) و مقايسه عملكرد آن با روش ارائهشده در [20] يرداخته مي بـشود.

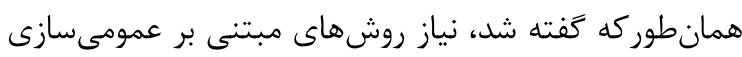

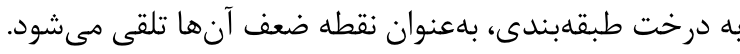

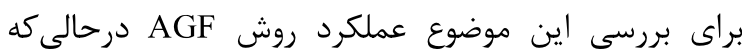

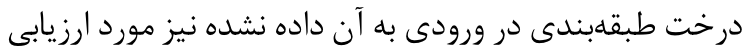

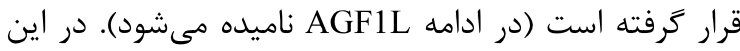

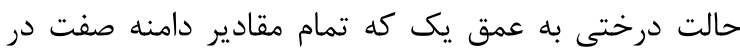
بركها و مقدار ANY در ريشه قرار دارد بلهورت خودمار بكار

$$
\text { ايجاد مىشود. }
$$

درخت تصميم مورد نياز روش پيشنهادئى توسط

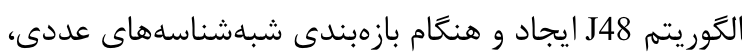

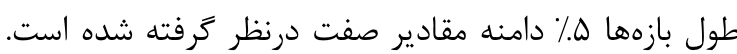

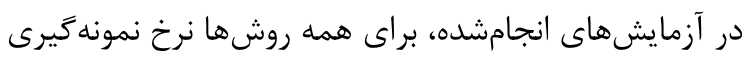

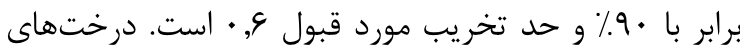

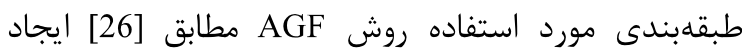
شدهاند.

روند ارزيابى دقت طبقهبندى، در شكل (9) نمايش داده

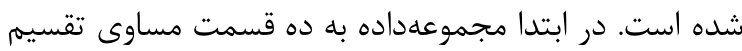

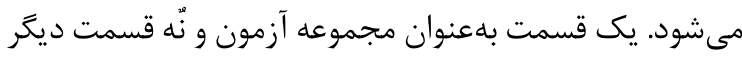
بهعنوان مجموعه آموزش انتخاب مىشود؛ سيس الكَوريتم

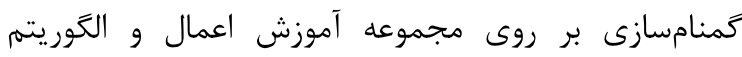

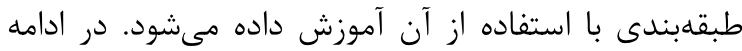

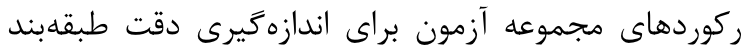

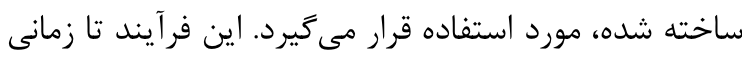
كه تمام ده قسمت بهعنوان مجموعه آزمون انتخاب شوند، ادامه مى يابد و در انتها ميانكَين دقت طبقدبندى در دمان تمام دورها

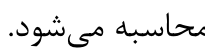

مراحل Q- مجموعهاى از شبهشناسهها ايجاد مى كند كه مقدارشان در ركورد r هنوز فرونشانده نشده است الهان شبهشناسهاى كه در انتها بازكردانده مى شعود از اين مجموعه (CQ)

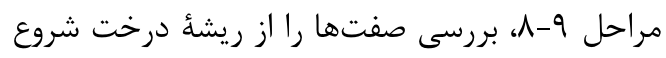
مى كند و تا زمانى كه كره فعلى يكى از برك إنهاى درخت

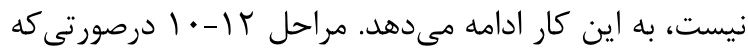

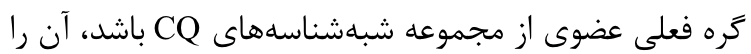
بهعنوان كماهميت ترين شبهشناسهاى كه تاكنون بررسى شده قرار مىدهد. همجنين حذف اين شبهشناسه از CQ موجب كني مىشود شبهشناسهاى كه بيش از يكبار در مسير ريشه تا برى ظاهر مىشود، فقط در نخستين دفعه مورد بررسى قرار

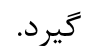
مراحل V| | | 19 بررسى مى كنند تمام شبهشناسهها در مسير ريشه تا درخت ملاقات شدهاند يا خير. درصورتى كه هنوز

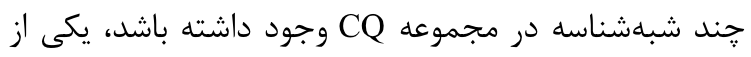
آنها بهصورت تصادفى بهعنوان شبهشناسه خروجى انتخاب مىشود. مرحله نوزده صفت qi را كه انتظار مىرود فرونشاندن آن تأثير كمى درنتيجه طبقهبندى داشته باشد درده در خروجى

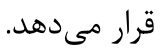

\section{ه- هيادهسازى طرح هيشنهادى و نتايج شبيهسازى و ارزيابى}

ييادهازى الكوريتم با استفاده از زبان جاوا و بهكمك كتابخانه

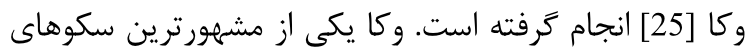

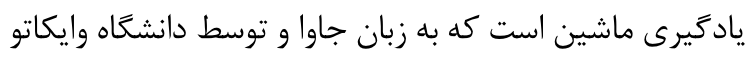

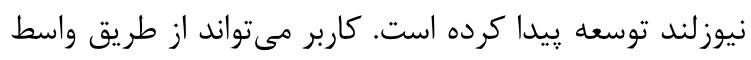

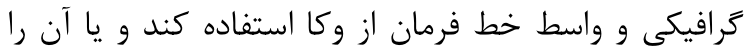

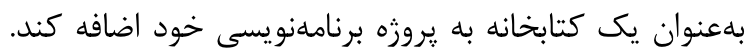

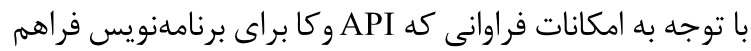

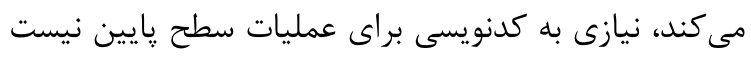

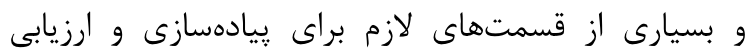

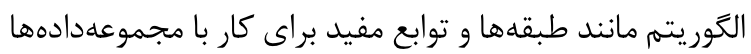
و الكوريتمهاى طبقهبندى، توسط اين كتابخانه انجام مى گيرد.

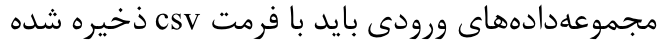
باشند. نخستين خط از فايل ورودى شامل نامدام صفات فردات \#QI مجموعهداده است. طبق قرارداد نام شبهشناسهها خاتمه مىيابد و آخرين صفت بهعنوان صفت حساس درنظ 


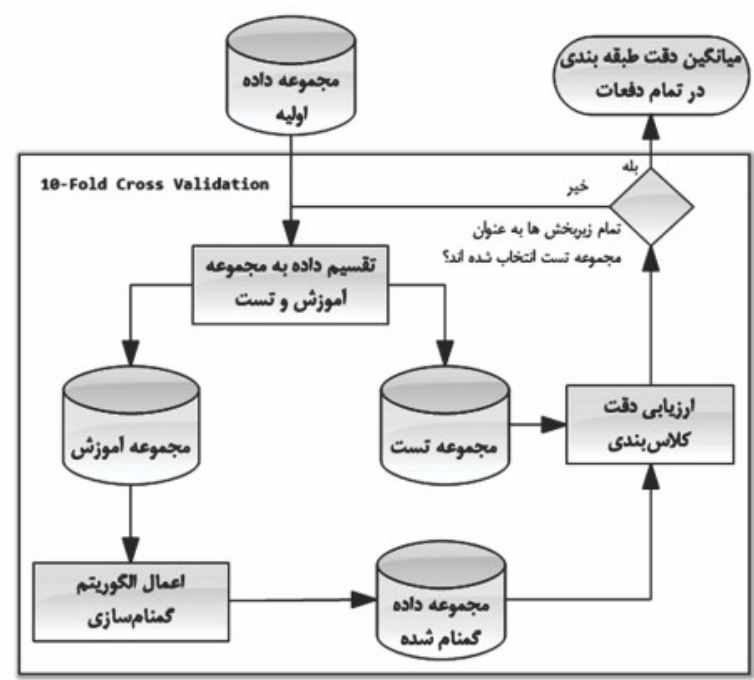

(شكل - ()): روند ارزيابى الكوريتمهاى كَمنامسازى

(Figure-6): Evaluation of anonymization algorithms

مجموعهداده مورد استفاده Adult [27] نام دارد كه در كارهاى زيادى از آن براى ارزيابى طبقهبندى استفاده شده

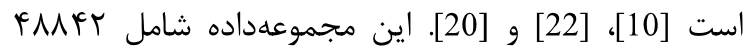
ركورد و يانزده صفت است.

صفت طبقه، ميزان درآمد يك فرد در طول ساكده سال (Income) باشد. همين صفت بهعنوان صفت حساس نيز درنظر گرفته

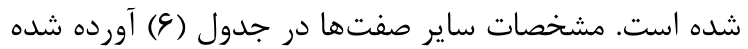

براى انجام آزمايشهاى مختلف צ، 9 و را I صفت از

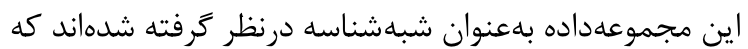
بdترتيب Adult.6، Adult.9 و Adult.12 ناميده مي شوشوند. صفتهايى كه در هر يك از اين حالات بهعنوان شبهشناسه انتخاب شدهاند در جدول (V) قابل مشاهده است.

(جدول - (9): صفتهاى مجموعهداده Adult

(Table-6): Atributes of Adult Data set

\begin{tabular}{|c|c|c|c|c|c|}
\hline تعداد/دامنه مقادير & نوع & صفت & تعداد/دامنه مقادير & نوع & صفت \\
\hline 14 & كسسته & Occupation & $17-90$ & ي پِيوسته & Age \\
\hline 8 & حَستته & Work-class & $0-99999$ & ي ي يوسته & Capital-gain \\
\hline 7 & كسسته & Martial-status & $0-4356$ & ييوسته & Capital-loss \\
\hline 6 & كستسته & Relationship & $1-16$ & ي ي يوسته & Education-num \\
\hline 2 & كسسته & Sex & $13492-1490400$ & ي پيوسته & Final-weight \\
\hline 40 & كسسته & Native-country & $1-99$ & ي ي يوسته & Hours-per-week \\
\hline 5 & كسسته & Race & 16 & كستسته & Education \\
\hline
\end{tabular}

(جدول (Y)): صفتهاى انتخاب شده بهعنوان شبهشناسه

(Table-7): Selected attributes for quasi identifier

\begin{tabular}{|c|c|}
\hline Adult.6 & age, education, sex, race, occupation, native-country \\
\hline Adult.9 & age, education, sex, race, occupation, native-country, workclass, marital-status, capital-loss \\
\hline Adult.12 & age, education, sex, race, occupation, native-country, workclass, marital-status, capital-loss, \\
relationship, hours-per-week, capital-gain
\end{tabular}

نمايش داده شده است نتايج بلهدستآمده نشان مى دهد

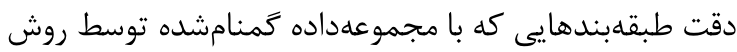

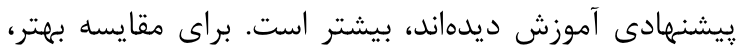
دقت طبقهبندى بر روى دادههاى گمنامنشده نيز اندازهخيرى

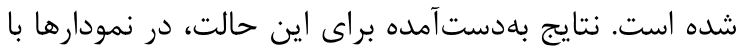

r-ه - دقت طبقهبندى

براى ارزيابى تأثير گمنامسازى بر دقت طبقهبندى از

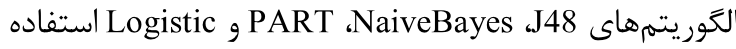
شده است. در نخستين آزمايش نُه صفت از مجموعهداده

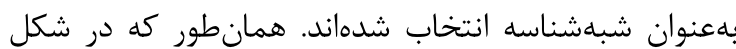


بيشتر است. با اين حال وقتى تعداد زيادى از صفتها بهعنوان

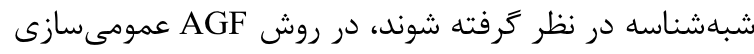

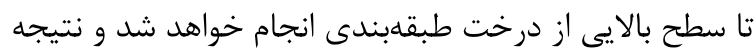

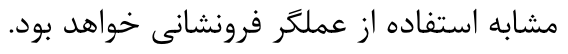

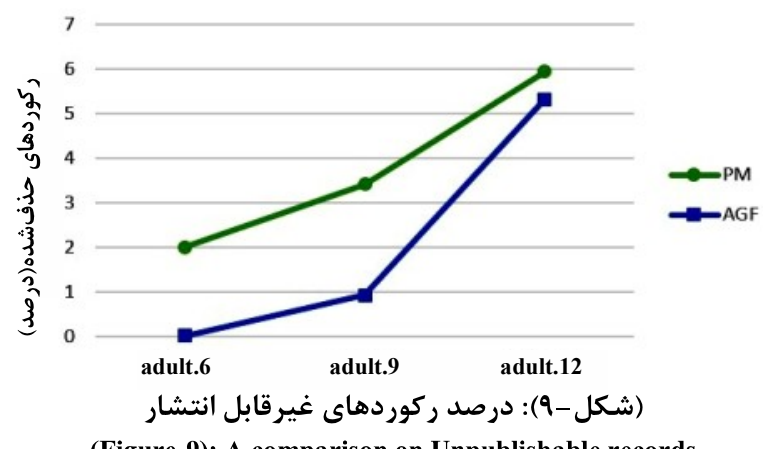

(Figure-9): A comparison on Unpublishable records

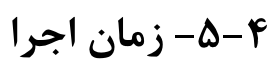

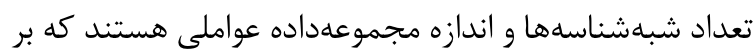

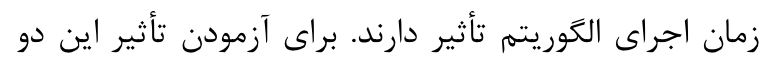

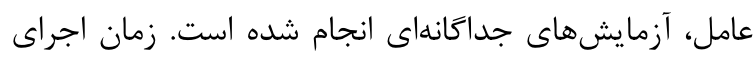

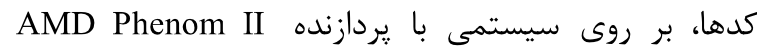
4GB و 1090T (3.2 GHz)

با افزايش تعداد شبهشناسهها نقاط تمايز ركوردها

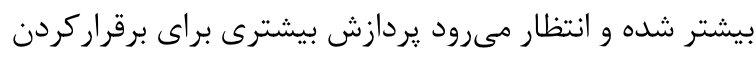

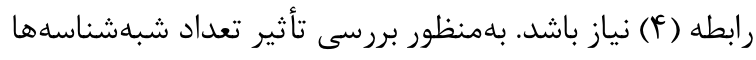

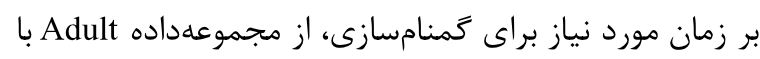

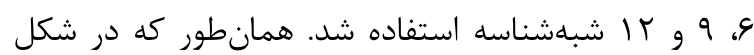

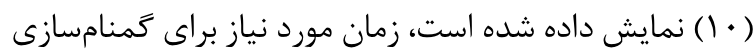

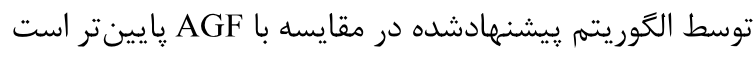
و همجنين تأثيريذيرى كمترى از تعداد شبهشناسهها دارد.

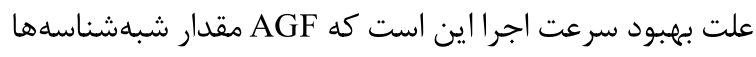

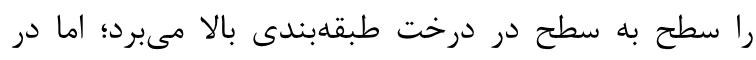

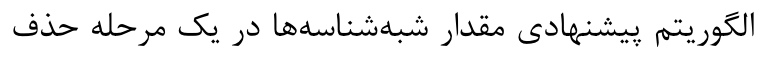

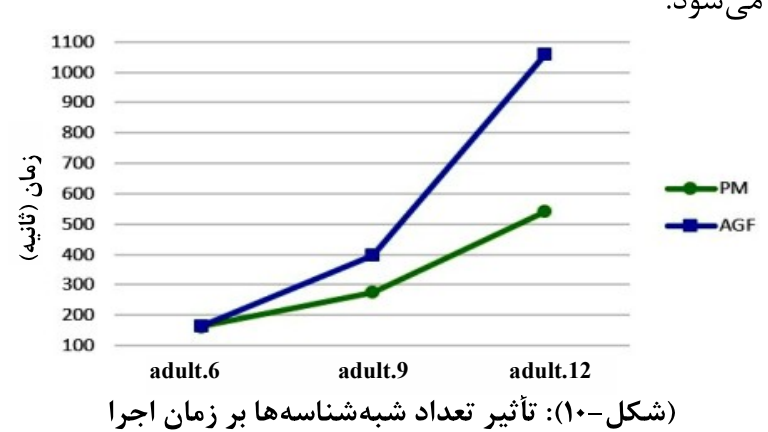

(شكل-•(1): تأثير تعداد شبهشناسهها بر زمان اجرا

(Figure-10): The impact of Quasi Identifiers on simulation run time
نام BL نمايش داده شده است. بهمنظور بررسى تأثير تعداد

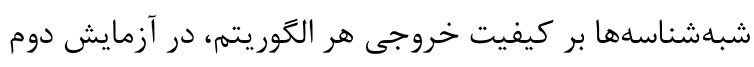

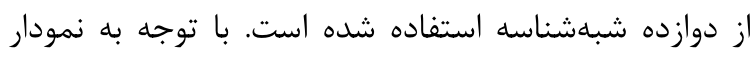

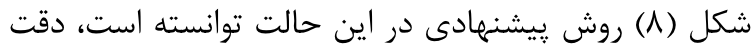

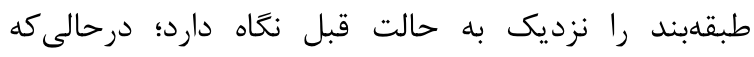
روشهاى AGF و AGF1L با افت دقت بيشترى مواجه

شدهاند.

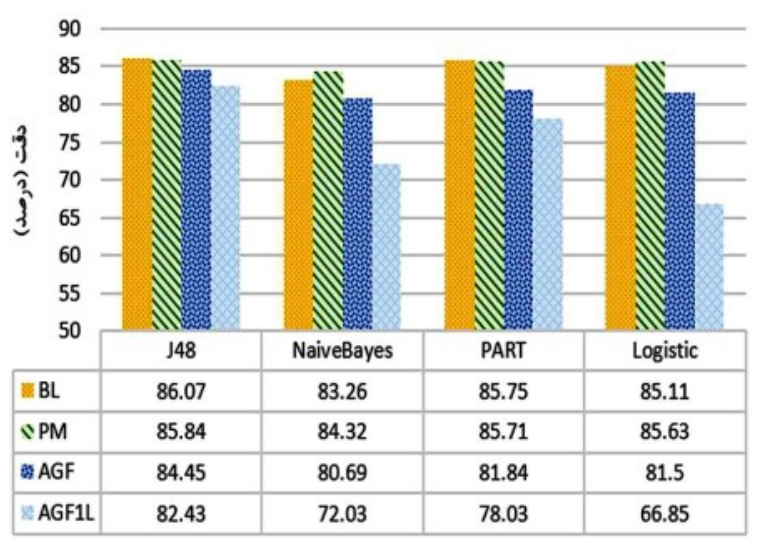

(شكل - (Ydult.9 دقت طبقدبندى - مجموعه داده

(Figure-7): Classification accuracy in Adult.9 Data set

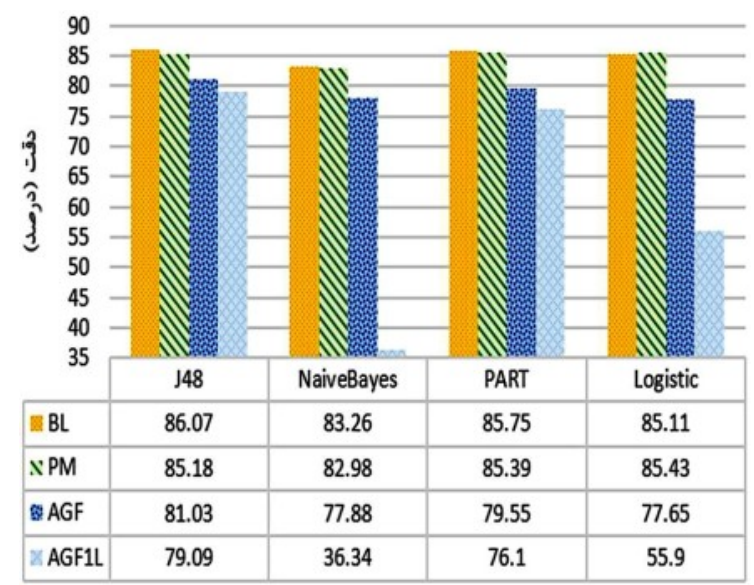

(شكل-1): دقت طبقهبندى - مجموعهداده Adult.12

(Figure-8): Classification accuracy in Adult.12 Data set

$$
\text { r-ه - ركور دهاى غيرقابل انتشار }
$$

كَفتهشد كه در طول اجراى الكوريتم عملكرهاى دستهسازى مقدار تعدادى از صفات هر ركورد را تغيير مى دهند و و بهوسيله

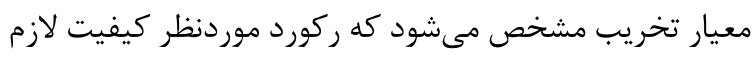

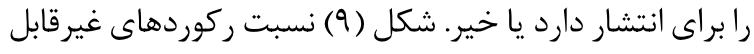

انتشار به كل ركوردهاى مجموعهداده را نشان مى دهدي. همانطور كه انتظار مىرفت، بهدليل استفاده از مجان

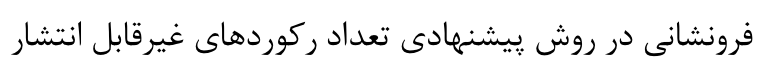


در طبقهبندى گمنام مىشوند و يا در حالتى كه ركوردهاى

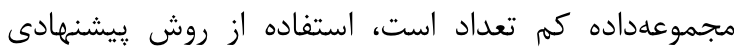

$$
\text { مناسب نخواهد بود. }
$$

\section{7-References}

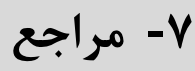

[1] B. C. M. Fung, K. Wang, A. Wai-Chee Fu and P. S. Yu, (2010), Introduction to PrivacyPreserving Data Publishing: Concepts and Techniques, Chapman and Hall/CRC.

[2] J. Bennett and S. Lanning, (2007), "The Netflix Prize", Proceedings of the KDD Cup Workshop, pp. 3-6.

[3] D. Nettleton, (2014), "Data Privacy and Privacy-Preserving Data Publishing," in Commercial Data Mining: Processing, Analysis and Modeling for Predictive Analytics Projects, Morgan Kaufmann, pp. 266-277.

[4] B. Fung, K. Wang and P. Yu, (2010), "PrivacyPreserving Data Publishing: A Survey of Recent Developments", ACM Computing Surveys, vol. 42 , no. 4 ,

[5] L. Sweeney, (2002), "k-Anonymity: A Model for Protecting Privacy", International Journal of Uncertainty, Fuzziness and Knowledge-Based Systems, vol. 10, no. 5, pp. 557-570.

[6] K. S. Babu, (2013), Utility-Based Privacy Preserving Data Publishing, $\mathrm{PhD}$ thesis, National Institute of Technology Rourkela.

[7] N. Mohammed, B. C. M. Fung, P. C. K. Hung and C. K. Lee, (2009), "Healthcare Data: A Case Study on the Blood Transfusion Service", Proceedings of the 15th ACM SIGKDD international conference on Knowledge discovery and data mining, pp. 1285-1294.

[8] D. Dou and S. Coulondre, (2012), "Detecting Privacy Violations in Multiple Views Publishing," in Database and Expert Systems Applications, Springer-Verlag Berlin Heidelberg, 506-513.

[9] A. Anjum and G. Raschia, (2013), "Anonymizing Sequential Releases under Arbitrary Updates", Proceedings of the Joint EDBT/ICDT 2013 Workshops, pp. 145-154.

[10]B. Fung, K. Wang and P. Yu, (2007), "Anonymizing Classification Data for Privacy Preservation", IEEE Transactions on Knowledge and Data Engineering, vol. 19, no. 5, pp. 711-725.

[11] V. S. Susan and T. Christopher, (2014), "A Survey on Privacy Preservation in Data Publishing", International Journal of Computer Science and Mobile Computing, vol. 3, no. 3, pp. $188-193$. بdمنظور بررسى ميزان مقياسيذيرى، در آزمايشهاى

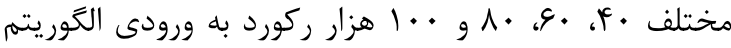

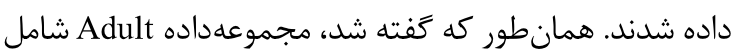

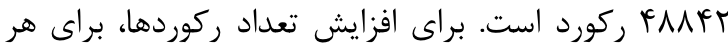
صفت، احتمال داشتن مقادير مختلف حساب شد؛ سيس بر بر بر

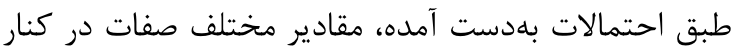
هم قرار داده شد و ركوردهاى مورد نياز توليد شدند. در اين آزمايش شش صفت بهعنوان شبهشناسه انتخاب شدند. نتايج بهدستآمده در شكل (1) (1) نمايش داده شده است.

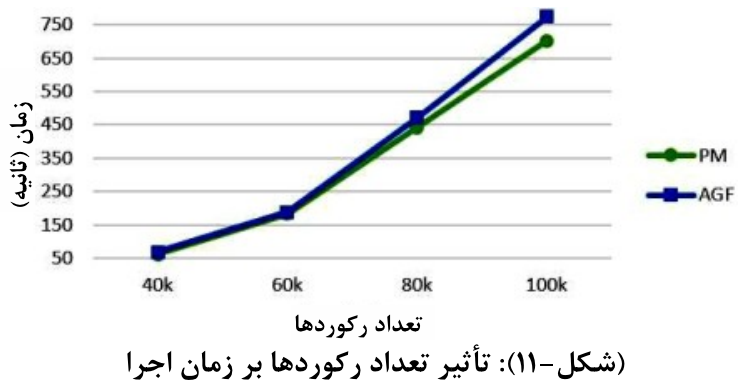

(Figure-11): The impact of records on simulation run time

(جدول-1): مقايسه روش بيشنهادى و AGF

(Table-8): Comparison of proposed technique with AGF

\begin{tabular}{|c|c|c|c|c|c|}
\hline طبقدبندى دقت & غ غوردهاى & زمان & طرخبه نياز به & كاربرد & روش \\
\hline بيشتر * & بيشتر & كمتر & خير & طبقهبندى & PM \\
\hline كمتر & كمتر * & بيشتر & بله & عام منظوره * & AGF \\
\hline
\end{tabular}

\section{9- - جمعبندى و نتيجه كيرى}

در اين مقاله استفاده از عمل جهارجوب محرمانگى تعريفشده در [20] مورد بررسى قرار برى كرفت و به جاى به كار گيرى عمومىسازى سلولى از فرونشاندن صفاتى كه بهرة اطلاعاتى كمترى دارند، استفاده به به شد. اگر جه عمل گر فرونشانى نسبت به عمومىسازى، مقدار

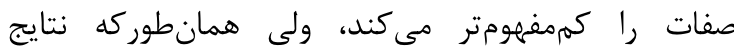
بهدستآمده نشان مىدهد، استفاده درست از اين عمل رلمر، علاوه بر اينكه مىتواند نتيجه طبقهبندى را نزديك به

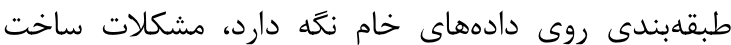
درخت طبقهبندى براى هر شبهشناسه را به همراه ندارد. در

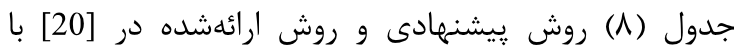
يكديخر مقايسه شدهاند. در هر ويزگىى، روشى كه عملكرد بهترى داشته با علامت ستاره(*) مشخص شده است. با توجه به اين جدول، در شرايطى كه دادهها با هدفى غير از استفاده 
Publishing", Journal of Information Security, vol. 4, no. 2, pp. 101-112.

[25] M. Hall, E. Frank, G. Holmes, B. Pfahringer, P. Reutemann and I. H. Witten, (2009), "The WEKA Data Mining Software: An Update", ACM SIGKDD Explorations Newsletter, vol. 11 , no. 1 , pp. 10-18.

[26]"Taxonomy trees of the Adult data set", [Online]. Available: http://ddm.cs.sfu.ca/dmsoft/Privacy/products/a dultHierarchy.txt. [Accessed 8 May 2016].

[27]"UCI Machine Learning Repository: Adult Data Set", [Online]. Available: http://archive. ics.uci.edu/ml/datasets/Adult. [Accessed 8 May 2016].

[28] M. Nergiz, C. Clifton and A. Nergiz, (2009), "Multirelational k-Anonymity", IEEE Transactions on Knowledge and Data Engineering, vol. 21 , no. 8 , pp. 1104-1117.

[Y?[مهدى صـــادق يور، " حفظ محرمانكى در انتشــــار

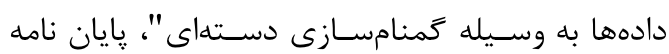

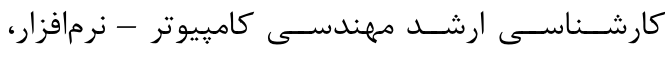

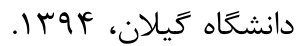

[29]Mehdi Sadeghpour, "Privacy Preserving Data Publishing using Group Based Anonymization", MSc thesis in Software engineering, University of Guilan, 2015.

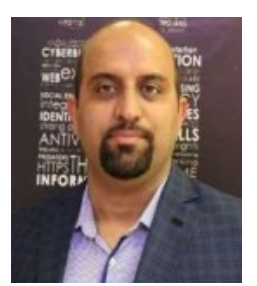
رضا ابراهيمى آنانى مدرى كارشناسى خود را از دانشعاه كيلان

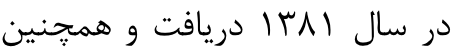
درجة كارشناسى ارشد و دركتراي

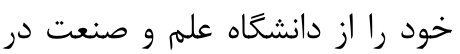

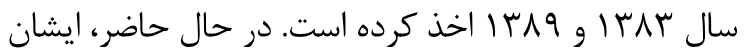

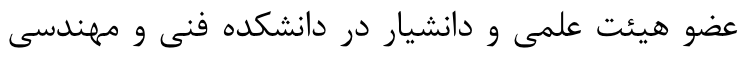
دانشخاه گيلان است. زمينههاى يزورهشى مورد علاقئ ايشان

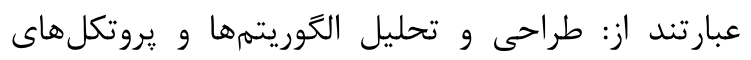
رمزنگارى و امنيتى جهت كاربرد در شبكهنهاى رائى رايانهاى و

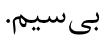
rebrahimi@guilan.ac.ir

$$
\text { نشانى رايانامٔ ايشان عبارت است از: }
$$

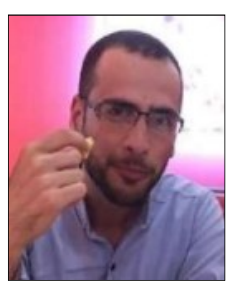

مهدى صادق يور مدرك كارشناسى

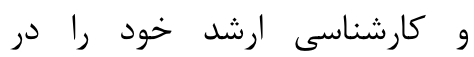

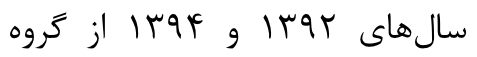
مهندسى كامييوتر دانشعاه گيلان اخذ كرد. موضوعات مورد علاقه كئد

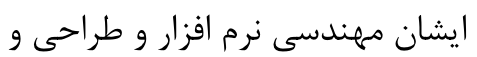
توسعه سامانههاى امن و با حفظ حريم خصوصى سنى سازمانى

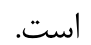

$$
\text { نشانى رايانامة ايشان عبارت است از: }
$$

mehdi.sadeghpour@live.com
[12] T. Dalenius, (1977), "Towards a Methodology for Statistical Disclosure Control", Statistik Tidskrift, vol. 15, 429-222.

[13] C. Dwork, (2006), "Differential Privacy," in Automata, Languages and Programming, Springer Berlin Heidelberg, pp. 1-12.

[14]K. Wang and B. C. M. Fung, (2006), "Anonymizing sequential releases", Proceedings of the 12th ACM SIGKDD International Conference on Knowledge Discovery and Data Mining, pp. 414-423.

[15] A. Machanavajjhala, D. Kifer, J. Gehrke and M. Venkitasubramaniam, (2007), "l-diversity: Privacy beyond k-anonymity", ACM Transactions on Knowledge Discovery from Data, vol. 1, no. 1, article 3.

[16] N. Li, T. Li and S. Venkatasubramanian, (2007), "t-Closeness: Privacy Beyond kAnonymity and 1-Diversity", IEEE 23rd International Conference on Data Engineering, pp. $106-115$.

[17] Y. Rubner, C. Tomasi and L. J. Guibas, (2000), "The Earth Mover's Distance as a Metric for Image Retrieval", International Journal of Computer Vision, vol. 40, no. 2, pp. 99 - 121.

[18]N. Li, T. Li and S. Venkatasubramanian, (2010), "Closeness A New Privacy Measure for Data Publishing", IEEE Transactions on Knowledge and Data Engineering, vol. 22, no. 7, pp. 943-956.

[19] M. E. Nergiz, M. Atzori and C. Clifton, (2007), "Hiding the Presence of Individuals from Shared Databases", InProc. of ACM International Conference on Management of Data, pp. 665-676.

[20] A. S. Sattar, J. Li, X. Ding, J. Liu and M. Vincent, (2013), "A general framework for privacy preserving data publishing", Knowledge-Based Systems, vol. 54, 276-287.

[21] K. Wang, P. Yu and S. Chakraborty, (2004), "Bottom-Up Generalization: A Data Mining Solution to Privacy Protection", Fourth IEEE International Conference on Data Mining, pp. 249 - 256.

[22] B. Fung, K. Wang and Y. P.S, (2005), "TopDown Specialization for Information and Privacy Preservation", Proc. 21st International Conference on Data Engineering, pp. 205-216.

[23] S. Kisilevich, L. Rokach, Y. Elovici and B. Shapira, (2010), "Efficient Multidimensional Suppression for K-Anonymity", IEEE Transactions on Knowledge and Data Engineering, vol. 22, no. 3, pp. 334 - 347.

[24] A. Hussien, N. Hamza and A. Hefny, (2013), "Attacks on Anonymization-Based PrivacyPreserving: A Survey for Data Mining and Data

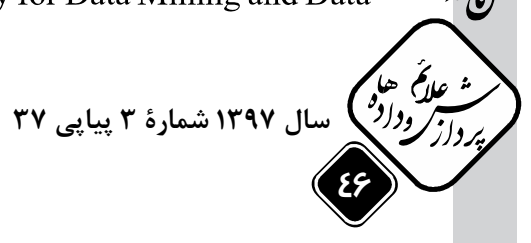

